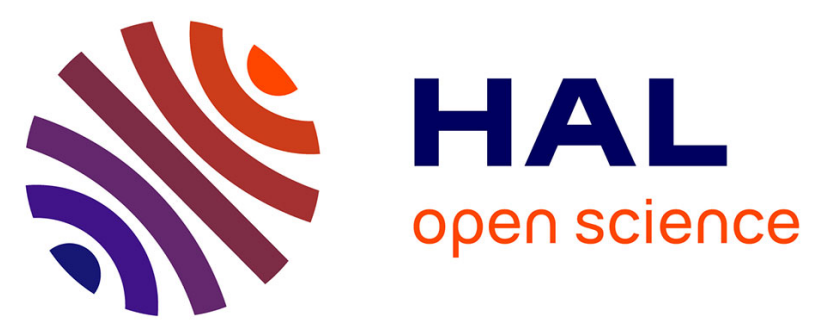

\title{
Assessment of functional nanomaterials in medical applications: can time mend public and occupational health risks related to the products' fate?
}

Christophe Bressot, Alexandra Aubry, Cécile Pagnoux, Olivier

Aguerre-Chariol, Martin Morgeneyer

\section{To cite this version:}

Christophe Bressot, Alexandra Aubry, Cécile Pagnoux, Olivier Aguerre-Chariol, Martin Morgeneyer. Assessment of functional nanomaterials in medical applications: can time mend public and occupational health risks related to the products' fate?. Journal of Toxicology and Environmental Health, Part A: Current Issues, 2018, 81 (19), pp.957-973. 10.1080/15287394.2018.1477271 . hal-02178768

\section{HAL Id: hal-02178768 \\ https://hal-unilim.archives-ouvertes.fr/hal-02178768}

Submitted on 3 Aug 2021

HAL is a multi-disciplinary open access archive for the deposit and dissemination of scientific research documents, whether they are published or not. The documents may come from teaching and research institutions in France or abroad, or from public or private research centers.
L'archive ouverte pluridisciplinaire HAL, est destinée au dépôt et à la diffusion de documents scientifiques de niveau recherche, publiés ou non, émanant des établissements d'enseignement et de recherche français ou étrangers, des laboratoires publics ou privés. 
Assessment of Functional Nano-Materials in Medical Applications: Can

Time Mend Public and Occupational Health Risks Related to the Products' Fate?

\section{Short title}

Assessment of Functional Nano-Materials

\section{Authors}

Dr Bressot, Christophe

Direction de risques chroniques

Institut National de l'Environnement Industriel et des Risques (INERIS)

Verneuil en Halatte, France

christophe.bressot@ineris.fr

Pr Alexandra Aubry

Sorbonne Universités

Université Pierre et Marie Curie

Faculté de Médecine, Laboratoire de Bactériologie

Centre National de Référence des mycobactéries et de la résistance des Mycobactéries aux antituberculeux

Centre d'Immunologie et des Maladies Infectieuses (Cimi-Paris), INSERM U1135, équipe 13

91, boulevard de l'hôpital

Paris, France

alexandra.aubry@upmc.fr 
Pr Pagnoux, Cécile

Centre Européen de Céramiques

12 rue Atlantis

Limoges, France

cecile.pagnoux@unilim.fr

Dr Aguerre-Chariol, Olivier

Direction des Risques Chroniques

Institut National de l'Environnement Industriel et des Risques (INERIS)

Verneuil en Halatte, France

olivier.aguerre-chariol@ineris.fr

Dr.-Ing. habil. Morgeneyer, Martin

Sorbonne Universités,

Université de Technologie de Compiègne (UTC)

Génie de Procédés Industriels

Compiègne, France

martin.morgeneyer@utc.fr

\section{CORRESPONDING AUTHOR}

Morgeneyer, Martin martin.morgeneyer@utc.fr 


\section{Abstract}

Surface coatings are one promising option to prevent bacterial adhesion and biofilm formation given the prevalence of antibiotic resistant bacterial strains. $\mathrm{TiO}_{2}$ is presently considered to be the only photocatalytic material suitable for commercial use, although the toxicity risks of $\mathrm{TiO}_{2}$, particularly in its nanoparticulate form, have been addressed.

The release of nanoparticles from functional materials for medical applications and their aerosol formation has been studied. Furthermore, the fate of the material with respect to its product lifetime is investigated.

The present study affirms this risk since released submicronic and inhalable manufactured nano-objects, their agglomeraates or aggregates (NOAA) containing Ti have been found. The coating of the material magnifies its emission levels when comparing the obtained product properties to those of an uncoated sample.

The evolution of release tendecy with the material's time of use shows the release does not vanish with the continuous material losses induced by the release, thus the risk does not reduce with time. Consequently, this nanomaterial should rather be avoided in healthcare settings, or, alternatively, new $\mathrm{TiO}_{2}$ deposition techniques need to be developed.

\section{Keywords}

Nano-sized titanium dioxide, Anti-bacterial agents, aerosols, material aging, environmental exposure, Floors and Floorcoverings, Public and Occupational Health

\section{INTRODUCTION}

The scientific study of hospital or nosocomial cross infection began in the 1740s with the works of Sir John Pringle (Selwyn 1991). The rising awareness led to a wide spectrum of 
studies related to the bacterial adhesion to surfaces, since they present a serious societal, i.e. economical and health, problem (Swartjes et al. 2015). Microbial biofilms are ubiquitous in nature and their economical and health impacts has become a major topic in the healthcare sector (Donlan 2002).

While significant progress has been made regarding the prevention of healthcare-associated infections (HAI), many challenges remain to be addressed. For example, the Centers for Desease Control and Prevention reported that on any given day, about one in 25 hospital patients has at least one healthcare-associated infection (Prevention 2014). In 2014, results of the survey also known as the 'HAI Prevalence Survey' (Magill et al. 2014) described the burden of HAIs in U.S. hospitals. The survey report from 2011 estimated about 722,000 HAIs in U.S. acute care hospitals, besides about 75,000 patients with HAIs died during their hospitalizations. Health care settings are an environment of congregation of both infected persons as well as those of increased risk of infection (Ducel, Fabry, and Nicolle 2002). As soon as infected patients or other carriers of pathogenic microorganisms are admitted to hospitals, they can be considered as potential sources of infections for patients and staff (Inderdeep Singh Walia and Borle 2012). Furthermore, newly infected patients are an additional source of infection. The conditions in the hospital, be it crowding, transfers of infected patients from one unit to another, and accumulated presence of patients highly susceptible to infection in one area (e.g. newborn infants, burn patients, intensive care ) may contribute to the spread of nosocomial infections (Kamsu-Foguem, Tchuenté-Foguem, and Foguem 2014). The microbial contamination of the objects, devices, and materials may possibly get in contact with the fragile parts of a patient's body (Gunawardana 2013).

Given the prevalence of antibiotic resistant bacterial strains (Swartjes et al. 2015), surface coatings can be a promising option to prevent bacterial adhesion and biofilm formation. These films have been an area of concern in the field of orthopedic implants for years (Kargupta et 
al. 2014), thus its prevention using different types of antimicrobial surface treatments is of particular interest. Surface treatments that have been used include polyethylene glycol modification of polyurethane surfaces (Park et al. 1998), 'lotus effect' self-cleaning surfaces (Palgrave 2005), silver-containing surfaces (Lansdown 2006) etc. A more recently discovered family of antimicrobial surface treatments is based on the use of the photocatalytic titanium dioxide (T. Matsunaga 1985). As key reaction under UV irradiation, $\mathrm{TiO}_{2}$ produces a hydroxyl radical at the surface, capable of oxidizing most organic substances hereon (W. A. Jacoby 1998). These radicals are highly reactive for the inactivation of bacteria and viruses (Talebian, Nilforoushan, and Zargar 2011). At present, $\mathrm{TiO}_{2}$ is considered to be the only material suitable for commercial use, exhibiting photocatalytic properties (Hashimoto, Irie, and Fujishima 2005).

Each of the above mentioned techniques exhibit possible drawbacks such as the toxicity of antimicrobial agents (Takayama et al. 1995), the cytotoxicity of silver ions (B. S. Atiyeh 2007) as side effects of the antimicrobial effect, thus possibly contributing to the list of substances associated with increasing environmental concern (Tollefsen and Kacew 2017). However, in the case of $\mathrm{TiO}_{2}$ these risks seem to be low (Bernard et al. 1989), however they cannot be neglected completely (Heinrich et al. 1995). But, this distinction is sometimes trivialized in the literature as the material is even "considered to be environmentally friendly" (Hashimoto, Irie, and Fujishima 2005) sincemanufacturers assume the primary particles to remain in their matrix and given the maturity of the substance, its safety is considered to be "guaranteed by history" (see previous reference). Inhalation as the primary route for exposure (Lee and Kacew 2012) can lead to lung tumors in rats as shown by long-term toxicological studies (Shi et al. 2013). Also, other routes such as oral exposure have toxicologically been shown to be genotoxic, clastogenic and are known to cause moderate inflammation (Trouiller et al. 2009) (Skocaj et al. 2011). 
Similar to the dilemma when using nanoparticles in nanomedicine (Zhao and Castranova 2011), the benefits of this type of surface treatment, i.e. antimicrobial effects might be superposed by the objectionable effects of the $\mathrm{TiO}_{2}$ nanoparticles, such as exposure to the patients and healthcare workers, thus posing potential risks for both public and occupational health.

In this perspective, the ancient oath "primum non nocere, secundum cavere, tertium sanare" (first, do not harm, second, be prudent, and third, heal) gets an entirely new meaning. Not only the direct medical choices and interventions are questioned, but also the design choices of healthcare premises could 'heal and harm' at once. Answering this fundamental question whether functional materials for medical applications heal or harm workers and patientsnecessitates the study of particle release mechanisms which can bring these particles on their way to form an aerosol and then continue via their inhalation route towards human exposure. The study of exposure is, next to the study of toxicity and the study of dose-response is one of the three pillars of the practice of risk assessment. (Paustenbach 2000), (Krewski et al. 2007). The toxicity (Shi et al. 2013) and dose-response (Thorén 1992) of the used pristine material are not investigated here. This study contributes towards the third pillar with a focus on the particle release mechanisms from antibacterial tiles.

Firstly, the nanoparticle release from functional materials for medical applications and their aerosol formation is studied. As release scenario, mechanical wear of the surface is retained: A normal load is applied to an abrader, which is placed on the coated surface and then moved tangentially (Shandilya, Le Bihan, and Morgeneyer 2014). Normal load levels of $100 \mathrm{~g}$ corresponding to real life conditions (D4060 2007) are applied and the tangential wear movement is repeated up to 150 times during abrasion test cycles of 10 minutes, i.e. at higher frequencies than real life conditions would require. Thus, this wearing could be considered as a form of ageing. Various further wear mechanisms and instrumentation involved during 
stress application and aerosolization of wear particles have been investigated by different authors (Shandilya, Le Bihan, and Morgeneyer 2014). The method presented here has already successfully been applied to building materials with nano $\mathrm{TiO}_{2}$ coatings (Shandilya et al. 2014) and is an international standard test method for floorings (D4060 2007).

Secondly, the tile's fate with respect to its product lifetime is investigated. With the tile's time of use, the inherent product risks could rise, remain constant or decrease. Several scenarios are possible in this framework in order to mimic further stresses the product could undergo when ageing during its lifetime, beyond the mechanical wear. This simulated lifetime study is experimentally performed by means of a so-called accelerated weathering procedure, which is prescribed for building materials in international standards and has not been applied to other $\mathrm{TiO}_{2}$ coated building materials up until now (Shandilya et al. 2015).

\section{METHODS}

Together with the non-coated and non-weathered reference tiles, the overall test sample portfolio thus comprises of four types of tiles, which are subjected to weathering and or wear, see Figure 1. 


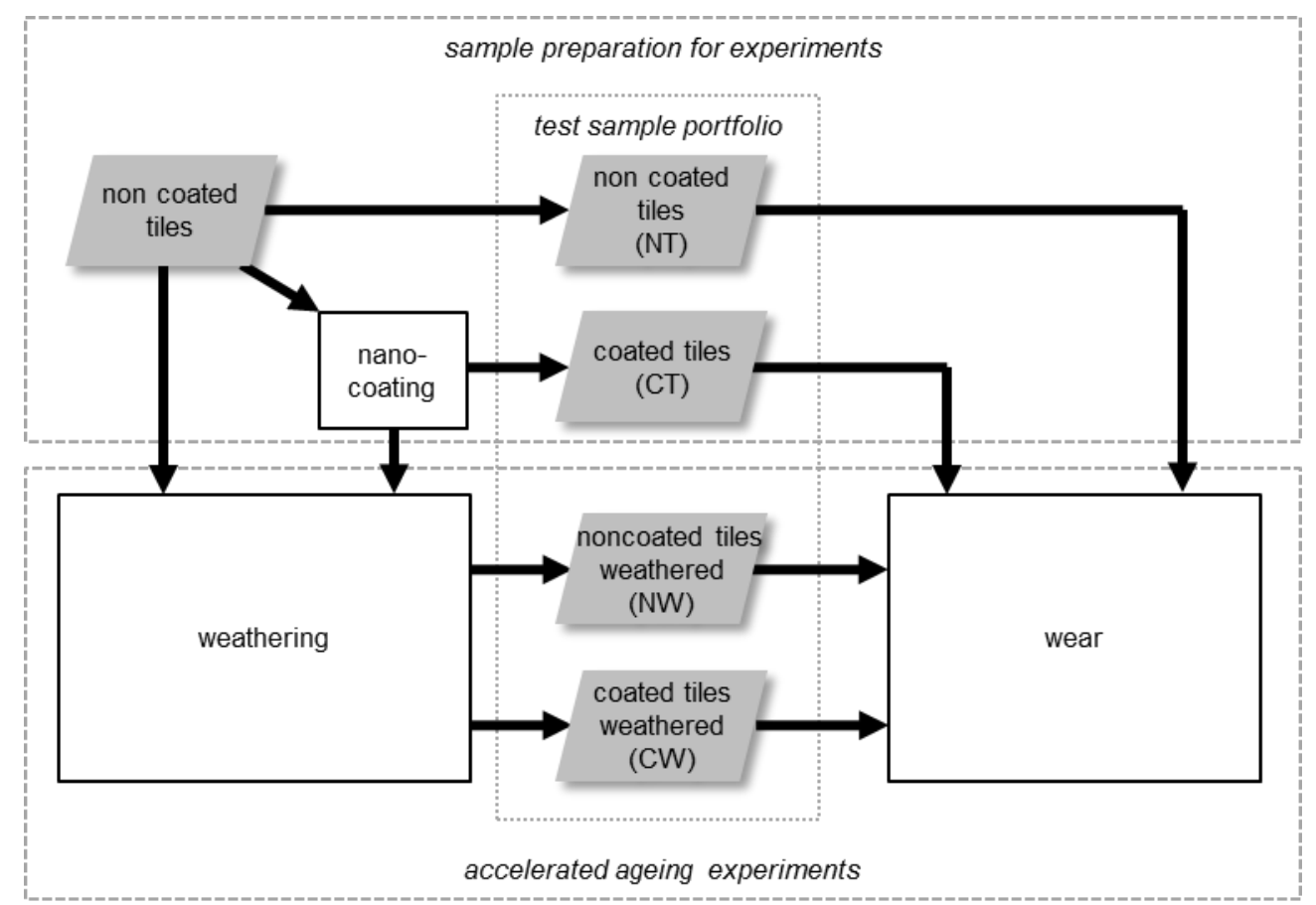

Figure 1: Test sample portfolio in the overall picture of sample preparations and accelerated ageing experiments

\subsection{Mechanical wear of tiles}

Several international standards define the abrasion tests for floor coverings of a series of materials such as stone (C241), unglazed tiles (84 2015) or different types of tiles (EN660-2). A Taber linear abrasion apparatus (Model 5750; Taber Inc. USA) was selected for the experiments for this study. The contact between the sample tile and the abrader (H38 abrader, Taber Inc. USA) is constantly vertically loaded by a weight. A motor unit allows for the backand-forth movement of the abrader on the fixed sample, adding a horizontal tangential abrasion to the vertical normal contact load (Figure 2). 


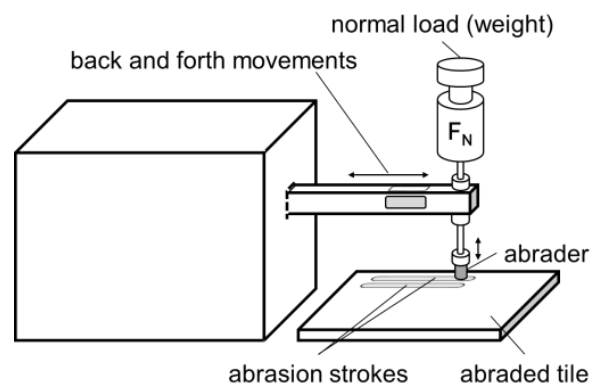

Figure 2: The linear Taber abrasion apparatus and abrasion of tiles study

A normal load of $100 \mathrm{~g}$ was selected for the tests. During 10 minutes of material testing, 150 tangential abrasion cycles (strokes) were performed.

\subsection{Weathering of tiles}

The accelerated weathering of coatings and other nonmetallic materials is defined in the ASTM standards (D6695 ; G151 ; G155). The samples are exposed to cycles of UV light irradiation, heat and watering. The tests were performed in a weathering chamber (Model Suntest XLS+; Atlas; Germany), based on the experimental conditions defined in (NF). For the UV source, a xenon arc lamp with an optical radiation filter $\left(300-400 \mathrm{~nm} ; 60 \mathrm{~W} / \mathrm{m}^{2}\right.$ Model NXE 1700; Ametek SAS; France) was used, with a maximum of 2658 cycles (which corresponds to an experiment duration of 7 months) of 2 hours each (continuous 120 min of UV light, 102 min dry, 18 min with water spray). The temperature during the UV exposure ranged between $35^{\circ} \mathrm{C}$ and $65^{\circ} \mathrm{C}$. De-ionized and purified water (conductivity $<1 \mu \mathrm{S} / \mathrm{cm}$ ) was used for the water spray onto the nanocoated samples. For example, Figure 3 shows nine cycles of weathering. 


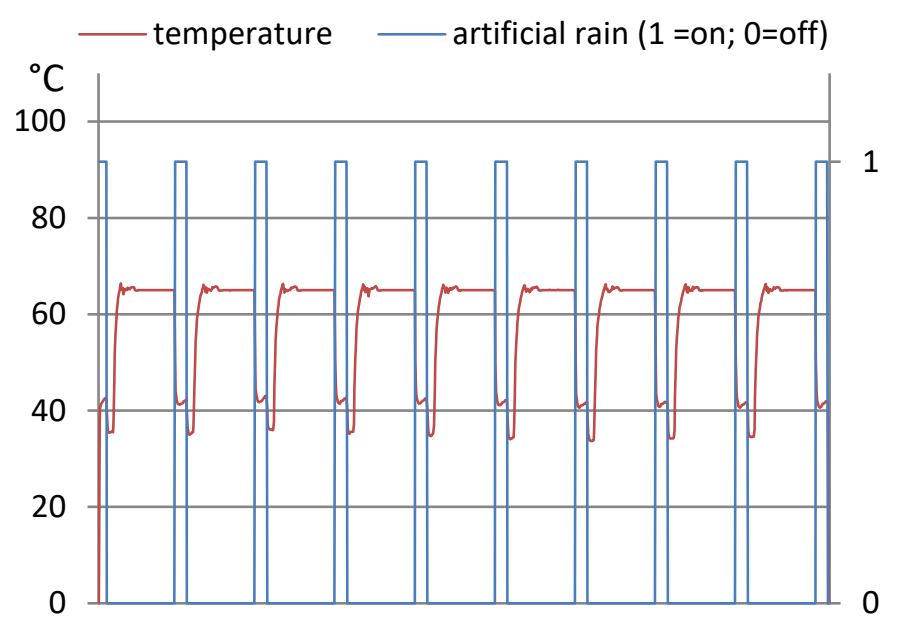

Figure 3: Temperature cycles and cyclic presence of artificial rain

\subsection{Aerosol characterization}

The four types of tiles investigated in this study are subjected to wear as described in section 2.1. The experimental wear setup is mounted in an emission chamber, which is for its part, mounted in a nanosecured facility. This two-fold sealing firstly, protects the worker from aerosol exposure and secondly, keep the background particle noise inside the chamber as low as possible (Le Bihan et al. 2014). The schematic representation of the overall setup is shown in Figure 4.

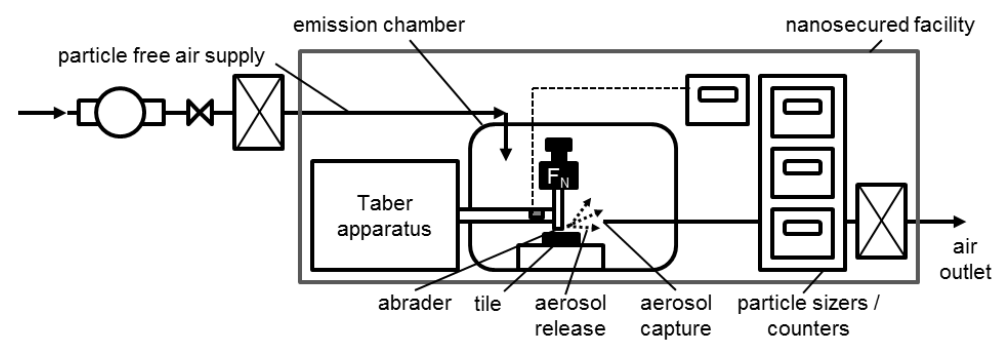

Figure 4: Experimental setup comprising a nanosecured facility, an emission chamber, a wear apparatus, and an aerosol 
Aerosols can be characterized by their mass and number concentrations with sizes in the range of $4 \mathrm{~nm}$ to $20 \mu \mathrm{m}$. For this, a condensation particle counter (CPC), a scanning mobility particle sizer (SMPS), an aerodynamic particle sizer (APS), and a Mini Particle Sampler (MPS; Ecomesure Inc.) are used. The particles collected by MPS are deposited on a porous copper grid (Model S143-3; Quantifoil Micro Tools GmbH Germany).

\subsection{Microscopical analysis}

The debris of particles from the aerosol which are collected on a microscope grid are characterized with a Transmission Electron Microscope (TEM, Model CM12; Philips, Netherlands), which allows obtaining micrographs with the front view of the primary particles and/or the agglomerates formed thereof.

\subsection{Further development of the experimental approach}

Contrary to the previous research carried out by (Shandilya et al. 2014, 2015) on nanocoated bricks which observed four successive phases of the abrasion process which led to the progressive degradation of coating and then brick, we observed a different abrasion process (see chapters 3 and 4). The findings by (Shandilya et al. 2014, 2015) were based on the investigation of the almost flat and horizontally continuous polymeric coating of bricks, i.e. a structure discontinuous in direction of penetration by the abrader. But, in this case, a coating is investigated which, due to its horizontally corrugated and discontinuous structure, performs vertically (i.e. in direction of penetration) like a monolithic material, the constituents are somehow smeared in space (Shandilya, Le Bihan, and Morgeneyer 2014). This requires a characterization approach which allows to describe and analyze the debris particles collected from the emitted aerosol. 


\subsection{Box-and-whisker diagrams}

The data analysis performed in this study covers the analysis of the aerosolization behavior of four different tile samples. It is characterized by the size distributions of the generated aerosols. This makes a statistical analysis necessary, which was carried on using the so-called box-whisker-plots. These diagrams allow interpretation of the data ranges measured and the shape of the distribution. Five points are represented for each sample, i.e. the median value in the center of the box, the upper and lower limits of the box represents an upper and lower percentile, $99 \%$ and $1 \%$ in our case, in order to indicate extreme values. Outside these statistical boundaries, individual values may be plotted. In conclusion, the box delimitates the size range within which $50 \%$ of the particles have been found, while the whiskers indicate a range of $98 \%$ particles as summarized in a representative figure (Figure 5).

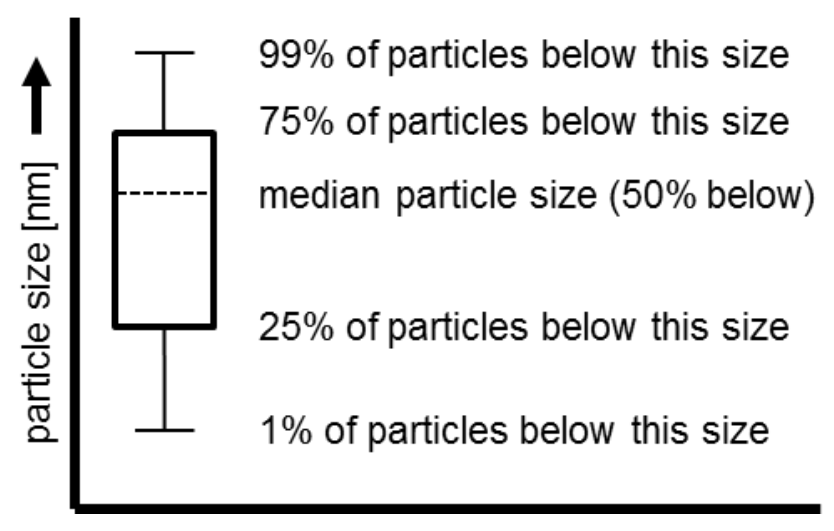

Figure 5: Graphical representation of particle size distributions by box-whysker-plots

\section{RESULTS}

\subsection{Analysis of the tiles' surfaces}

The morphological and chemical analysis of the surfaces of weathered and unweathered tiles enables an evolutive description of the tiles under weathering stresses. 
In order to identify the weathering/ ageing effect on the samples the following analysis focuses exclusively on the tiles presenting a tribologically changed surface. The tiles coated with nano- $\mathrm{TiO}_{2}$ shows very uneven surfaces, see Figure 6.
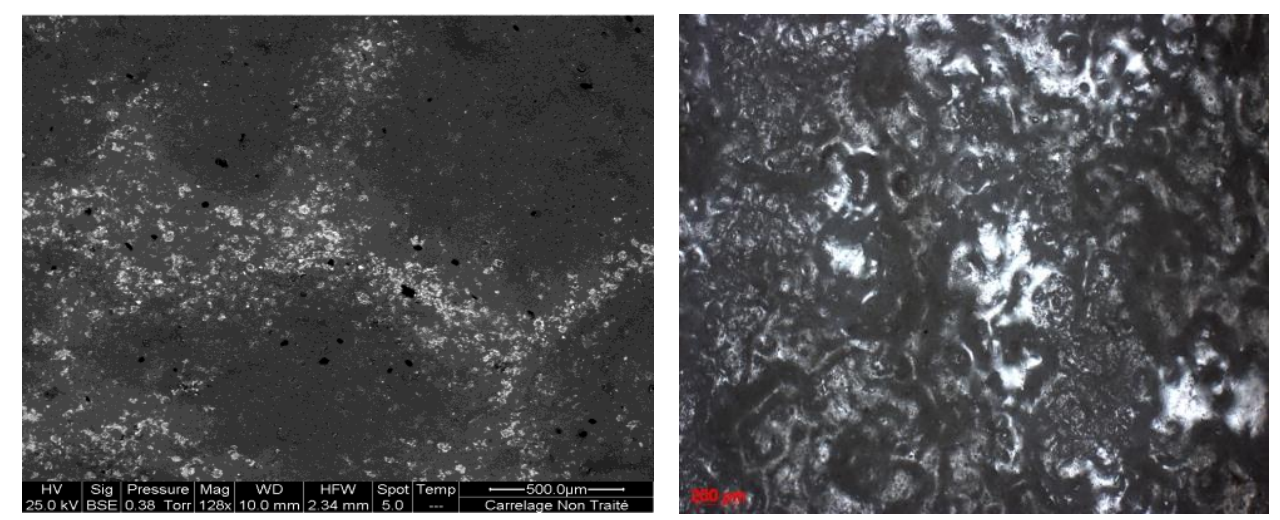

Figure 6:Non-treated tile (left) a treated tile (right). Both samples are neither weathered nor abraded

\subsubsection{Morphological analysis of unweathered tiles}

The SEM images of $\mathrm{TiO}_{2}$-nanocoated unweathered tiles shows big irregular forms on the tiles, corrugating the overall planar surfaces. These ridges are also microscopically observed since they are of about 200 to $600 \mu \mathrm{m}$ in width and cover the entire surface of the tiles. These observations could not be made on the NT samples.

The micrographs with magnification of 1600x shows the irregular morphologies where nano$\mathrm{TiO}_{2}$ is deposited. Spots containing NOAA of $\mathrm{TiO}_{2}$ are detected, see Figure 7. 


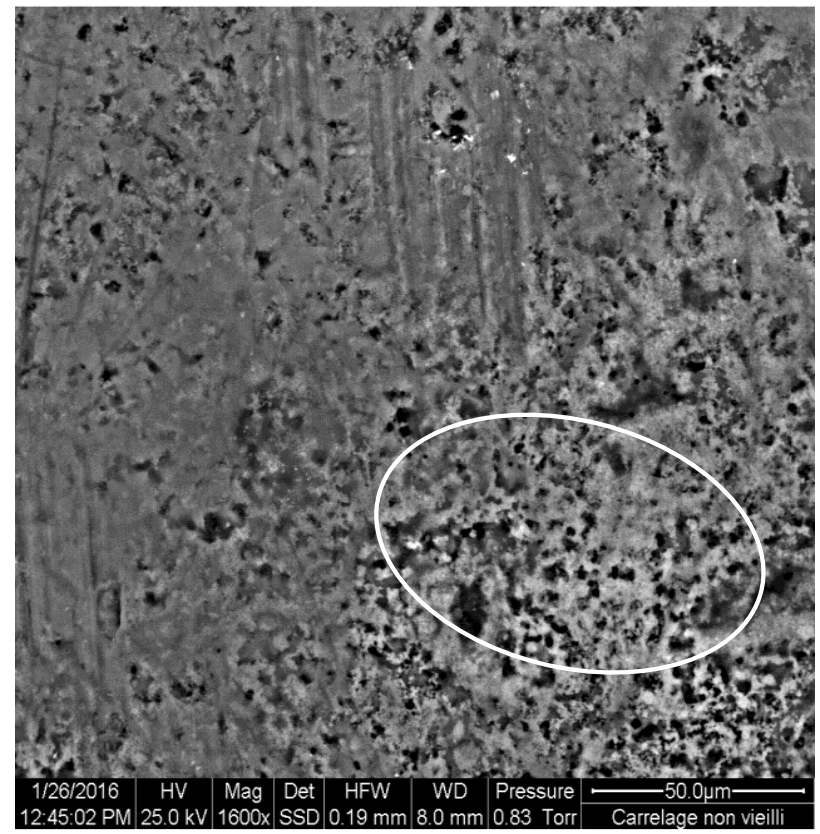

Figure 7: image of an unweathered tile (1600 X) with a spot zone (white ellipse) containing nano-TiO2, image width $200 \mu \mathrm{m}$

Magnification of 5000x yields more precise images where the deposition of nano- $\mathrm{TiO}_{2}$ is observed as cumulated huge micronic or supermicronic NOAA sintered on the tile surface. This sort of deposition on the tiles can be used at the workplace scale in an oven or more exceptionally using a high power $\mathrm{CO}_{2}$ laser (Fonseca et al. 2016). The thickness of the $\mathrm{TiO}_{2}$ deposition is close to or slightly greater than a micron. The ceramic surface observed in some rear hole is thought to be the nano- $\mathrm{TiO}_{2}$ deposition. 


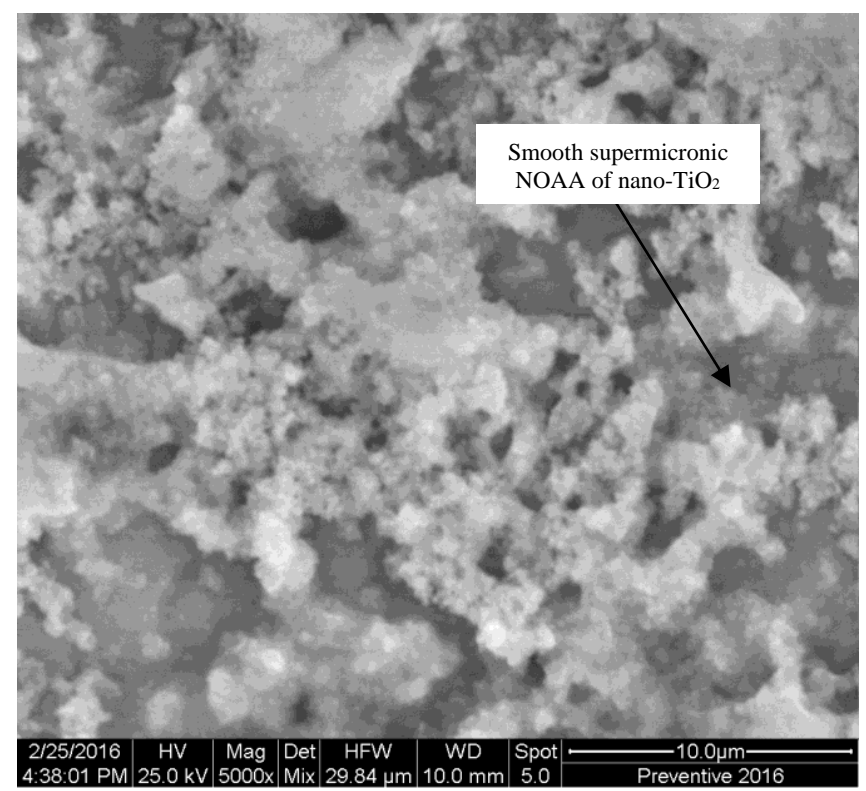

Figure 8: View of NOAA of nano-TiO2: smooth supermicronic objects are observed on the sample

\subsubsection{Morphological analysis of weathered tiles}

No significant modifications of the surface are observed at optical microscopy scale or at low magnifications (1600x) using the SEM. Occasionally, some free objects are detected on the surface, Figure 9.

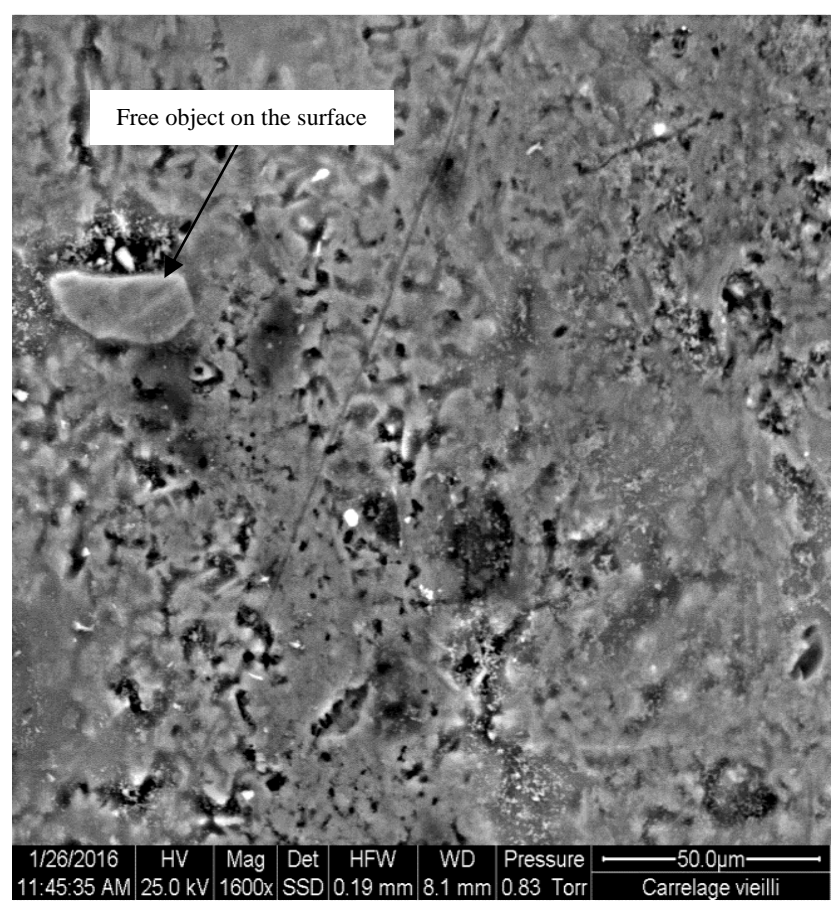

Figure 9: SEM image of weathered tile (1600 x) 
Some super-micronic nano- $\mathrm{TiO}_{2}$ NOAAs with a visibly smooth aspect compared to the main deposition surface, which are rather angular, granular and uneven. These smooth objects are observed for both the weathered and the unweathered tiles (see Figure 10).

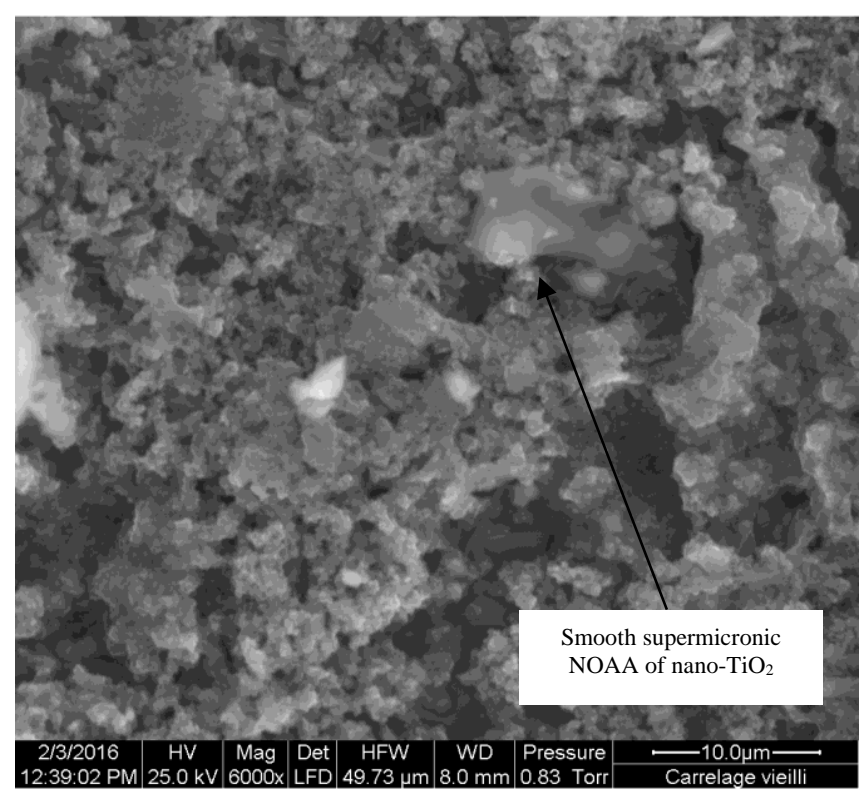

Figure 10: Smooth super-micronic NOAA found on weathered coated tile (mag. 6000x)

\subsubsection{Chemical analysis}

Chemical description of the initial (unweathered) and weathered tiles are analysed using a protocol developed which evaluates the chemical change from the results obtained from SEM analysis (seeFigure 11).

The main chemical difference between the non-treated and the nanotreated tiles is the irregular presence of $\mathrm{Ti}$ on the surface of the treated, photoactive tile. Furthermore, no significant evolutions were detected by the SEM for Ti, and neither for $\mathrm{Mg}, \mathrm{Al}, \mathrm{K}$, and $\mathrm{Na}$ due to artificial weathering. 


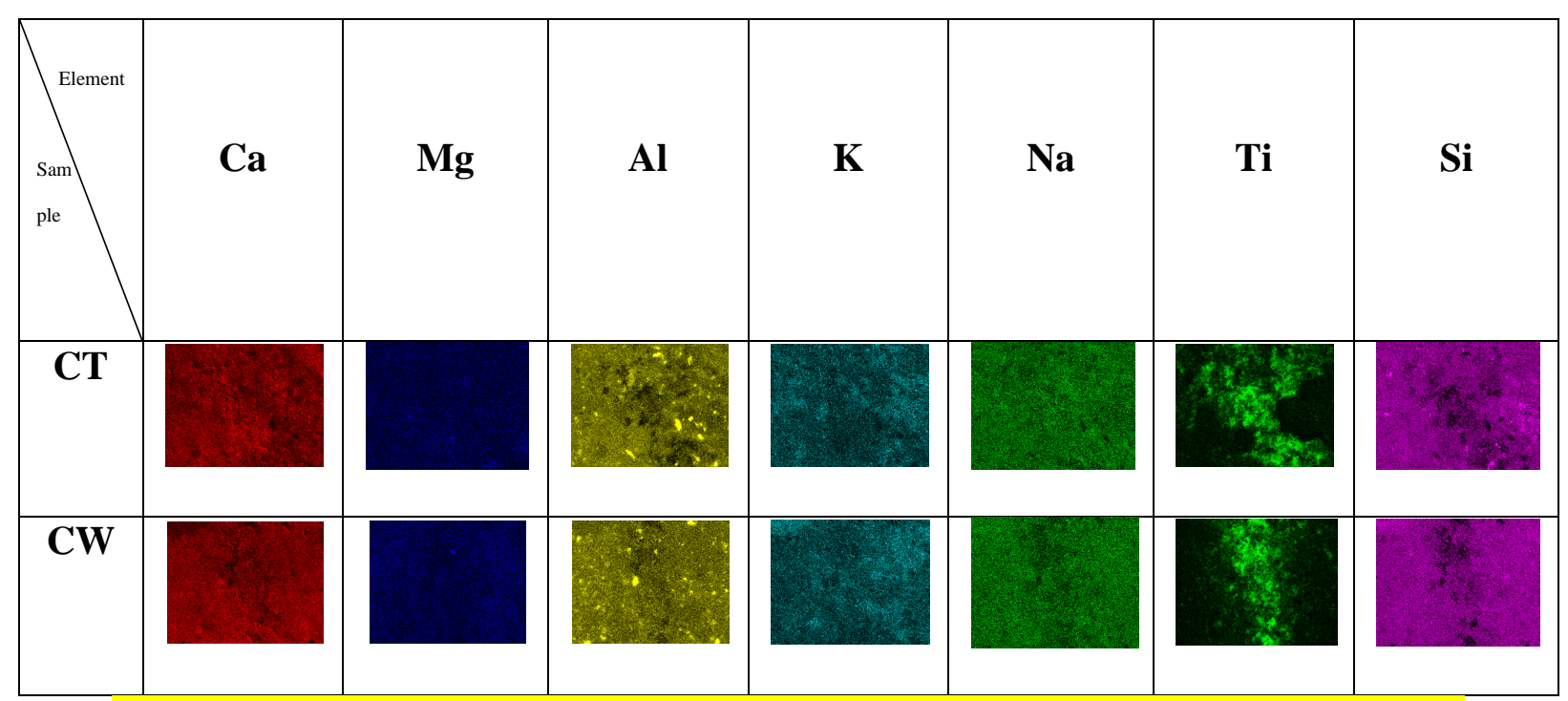

Figure 11: SEM mapping of the main elements on the unweathered coated tile $(C T)$ and the weathered tile $(C W)$.

A comparative study of the main chemical elements in the weathered and unweathered tile was conducted based on ten SEM measurements corresponding to a total surface of $50 \mathrm{~mm}^{2}$ for each sample. The calcium concentration detected by SEM is the main difference between the two tiles and also is the only chemical element, presence of which slightly decreased due to the weathering process (Figure 12). The decrease in calcium concentration (\%) between the unweathered and weathered samples from $8.1 \%$ to $7.2 \%$ is significant with respect to the confidence intervals.

Calcium is present in the ceramic matrix but also in the inorganic adhesive deposited on the ceramic during the process. Considering the tile's stability with respect to time, the moderate decrease might be related to the $\mathrm{CaO}$ present in the inorganic adhesive. As shown in Table 1, this inorganic adhesive leads to deploy $2 \%$ of $\mathrm{CaO}$, which is found in raw materials like lithic feldspars and calcium carbonate (Pellicelli, Tucci, and Rambaldi 2010) and is conceivably soluble in the spray water used in this study. This $\mathrm{CaO}$ might be washed out during weathering. 


\begin{tabular}{|l|l|l|}
\hline Oxide & Weight percentage & Raw material \\
\hline $\mathrm{SiO}_{2}$ & $43,1 \%$ & Lithium feldspar \& Silica \\
\hline $\mathrm{Al}_{2} \mathrm{O}_{3}$ & $3,9 \%$ & Lithium feldspar \\
\hline $\mathrm{B}_{2} \mathrm{O}_{3}$ & $24,5 \%$ & Orthoboric acid \\
\hline $\mathrm{BaO}$ & $8,8 \%$ & Barium carbonate \\
\hline $\mathrm{CaO}$ & $2,0 \%$ & Lithium feldspar \& Calcium carbonate \\
\hline $\mathrm{ZnO}$ & $4,9 \%$ & Zinc oxide \\
\hline $\mathrm{Na}_{2} \mathrm{O}+\mathrm{K}_{2} \mathrm{O}$ & $10,8 \%$ & Lithium feldspar \& Potassium carbonate \\
\hline $\mathrm{Li}_{2} \mathrm{O}$ & $2,0 \%$ & Lithium feldspar \& Lithium carbonate \\
\hline
\end{tabular}

The moderate damage over the surface of the tile surface could also be explained by a limited physical/chemical attack on this mineral implicating mainly Ca which is part of the matrix or the deposition on the surface.

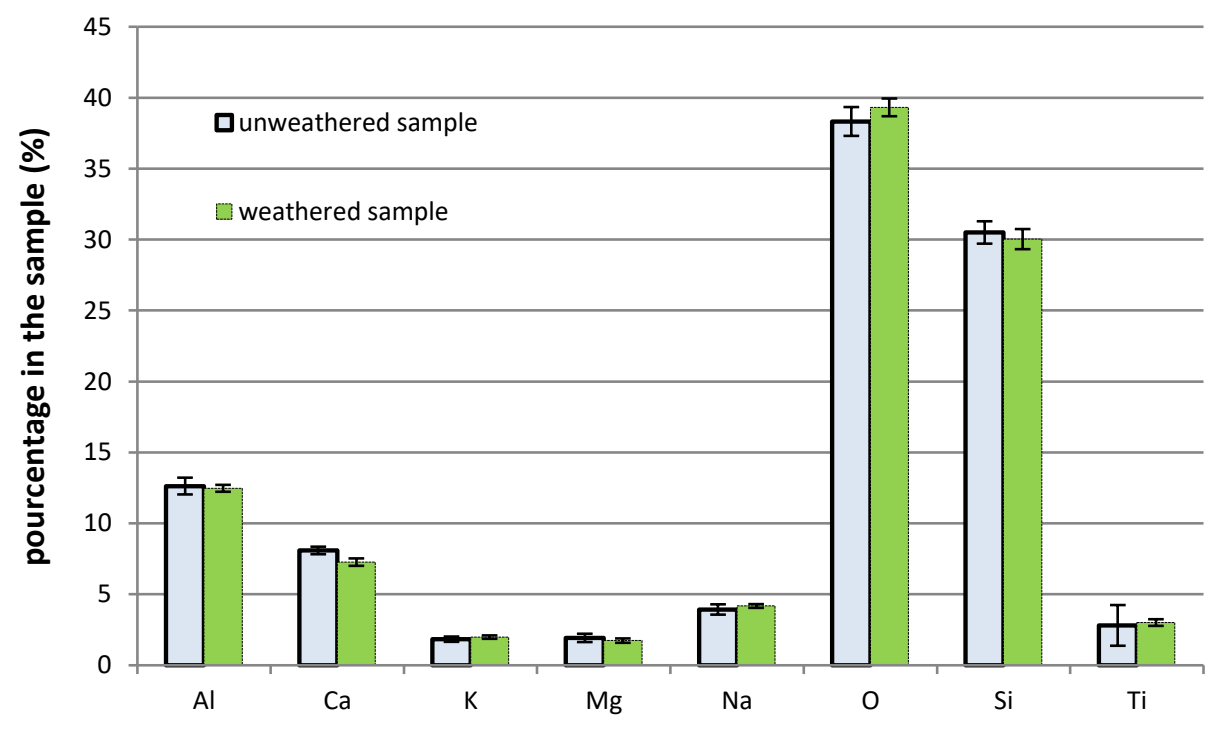

Figure 12: Relative presence of chemical elements in the sample 

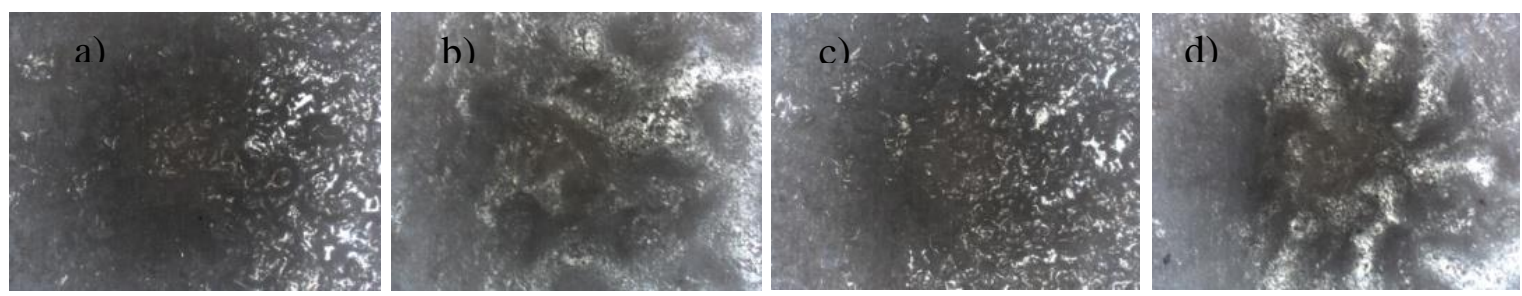

Figure 13: Optical microscopy of tile samples: a) Non coated and non-weathered (NT) but worn tile, b) coated nonweathered $(C T)$ worn tile, $c$ ) non coated weathered (NW, 7 month in climatic chamber)unworn tile, and d) coated and weathered ( $C W, 7$ month in climate chamber) unworn tile

\subsection{Analysis of the individual aerosol particles}

Sampling analysis carried out in our case can be divided in two parts. The first corresponds to the investigation of the classical formulation without nano- $\mathrm{TiO}_{2}$ deposed on the surface, i.e. $\mathrm{NT}$ and NW, and the second to samples with nano- $\mathrm{TiO}_{2}$, i.e. $\mathrm{CT}$ and $\mathrm{CW}$. The first part gives only ceramic matrix debris in form of mainly nanometric, submicronic or micronic particles. These results are not detailed in this work. We are going to focus on the sample analysis of nano coated tiles on the emission type of nano- $\mathrm{TiO}_{2}$.

For each abrasion test, two MPS samplings have been carried out, one during the first minute of the test, where nano-objects and their aggregates and agglomerates (NOAAs) are observed, the other during the last minute of the experiment, where fewer Ti is assumed to be present in the samples. This protocol aims to assess the changing composition of the aerosol during the abrasion test. The evolution of the aerosol from unweathered to weathered samples is moderate and concerns mainly the micronic NOAA of nano- $\mathrm{TiO}_{2}$. Only a few of these NOAAs are observed on the grid, present mostly as big micronic agglomerate on CT samples, whereas submicronic compact objects are observed on the grids from the CW samples. 
Table 2 Summary of the microscopically made observations of the objects on the TEM grids

\begin{tabular}{|c|c|c|c|c|c|c|c|}
\hline Sample & & $\begin{array}{l}\text { Presence } \\
\text { of } \\
\text { nanoobject } \\
\text { s }\end{array}$ & $\begin{array}{l}\text { Presence } \\
\text { of sub- } \\
\text { micron } \\
\text { sized } \\
\text { objects }\end{array}$ & $\begin{array}{l}\text { Presence of } \\
\text { micron } \\
\text { sized } \\
\text { objects }\end{array}$ & $\begin{array}{l}\text { Presence } \\
\text { of } \mathrm{TiO}_{2} \text { in } \\
\text { the objects }\end{array}$ & $\begin{array}{l}\text { Presen } \\
\text { ce of } \\
\mathrm{TiO}_{2} \\
\mathrm{NOAA} \\
\mathrm{s}\end{array}$ & $\begin{array}{l}\text { Presen } \\
\text { ce of } \\
\text { free } \\
\mathrm{TiO}_{2} \\
\text { particle }\end{array}$ \\
\hline $\mathrm{NT}$ & $\begin{array}{l}\text { abrasion } \\
\text { Starting }\end{array}$ & $+/-$ & $+/-$ & - & $\mathrm{T}$ & $\mathrm{T}$ & Inv. \\
\hline $\mathrm{NT}$ & $\begin{array}{l}\text { Abrasion } \\
\text { ending }\end{array}$ & & & & $\mathrm{N}$ & $\mathrm{N}$ & Inv. \\
\hline NW & $\begin{array}{l}\text { abrasion } \\
\text { Starting }\end{array}$ & $+/-$ & + & + & $\mathrm{T}$ & $\mathrm{T}$ & Inv. \\
\hline NW & $\begin{array}{l}\text { Abrasion } \\
\text { ending }\end{array}$ & + & + & + & $\mathrm{T}$ & $\mathrm{T}$ & Inv. \\
\hline $\mathrm{CT}$ & $\begin{array}{l}\text { abrasion } \\
\text { Starting }\end{array}$ & - & $+/-$ & + & $\checkmark$ & $\checkmark$ & $\mathrm{N}$ \\
\hline $\mathrm{CT}$ & $\begin{array}{l}\text { Abrasion } \\
\text { ending }\end{array}$ & - & $+/-$ & + & $x$ & $x$ & $\mathrm{~N}$ \\
\hline $\mathrm{CW}$ & $\begin{array}{l}\text { abrasion } \\
\text { Starting }\end{array}$ & - & $+/-$ & $+/-$ & $\checkmark$ & $\checkmark$ & $\mathrm{N}$ \\
\hline $\mathrm{CW}$ & $\begin{array}{l}\text { Abrasion } \\
\text { ending }\end{array}$ & - & + & $+/-$ & $x$ & $x$ & $\mathrm{~N}$ \\
\hline
\end{tabular}


$\checkmark=$ high; $\boldsymbol{x}=$ low $; \mathrm{T}=$ traces; $\mathrm{N}=$ no; $;-=$ very low presence of collected particles $;+/-=$ low presence of collected particles $;+=$ strong $;++$ very strong $;$ inv. $=$ invalid

\subsubsection{Analysis with respect to NT samples}

In the case of NT samples, the particles collected on the grid are mostly submicronic. Few nanometric or micronic particles are also present. Tile debris from the abrasion of the reference sample exhibits irregular shapes for all of the observed sizes. Versatile compositions are detected: the principal chemical elements detected within the particles are identified as $\mathrm{Zr}$, $\mathrm{Zn}, \mathrm{Si}, \mathrm{O}, \mathrm{Ca}$, and $\mathrm{C}$. Ti is present in small traces, i.e. $<5 \%$. Figure 14 shows some collected particles which allow to identify:

i) submicronic or nanometric ceramic matrix debris on the images a) and b),

ii) NOAAs of nanoTiO ${ }_{2}$ on the images d) to f). One third of the objects on the grid are considered to be submicronic NOAAs with approximate sizes between 100 $\mathrm{nm}$ and $600 \mathrm{~nm}$. The average size of the primary nano- $\mathrm{TiO}_{2}$ particles is close to 81 $\mathrm{nm}$ with minimum and a maximum sizes of 40 and $133 \mathrm{~nm}$, respectively. Most of them are quasi pure nano- $\mathrm{TiO}_{2}$ with traces of $\mathrm{Si}$ and $\mathrm{Ca}$.

No free nanosized $\mathrm{TiO}_{2}$ particles were detected.
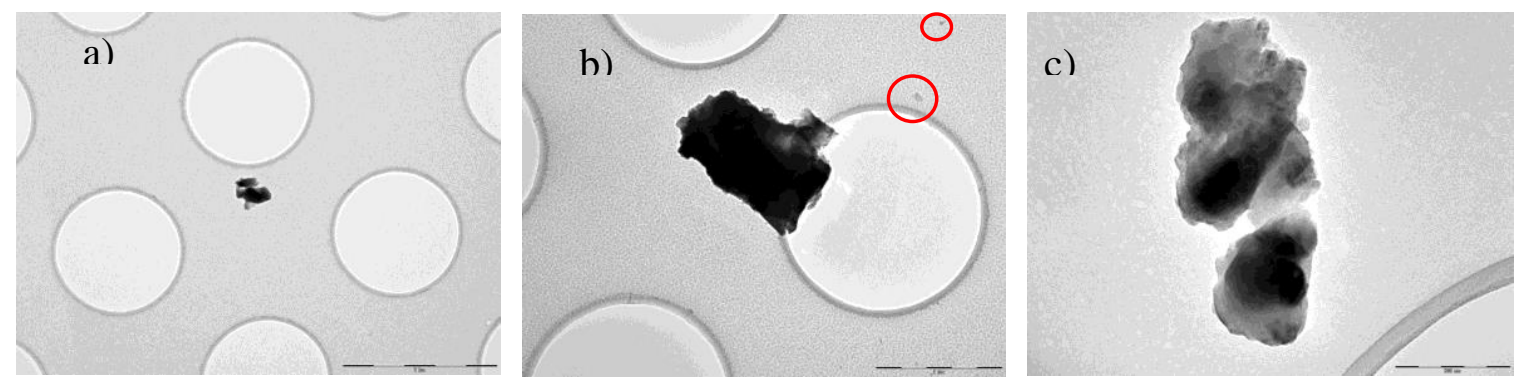

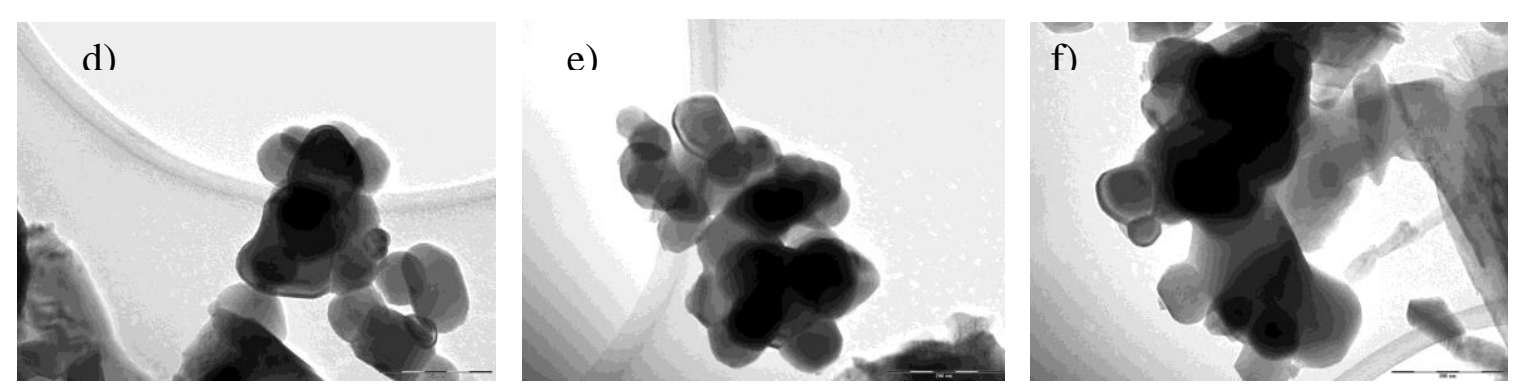

Figure 14: particles or NOAA collected on the TEM grid during the abrasion test using NT. The particle in a) is dominated by Si; Particles in b) are dominated by $\mathrm{Zr}(97 \%)$. c) composite containing nanoTiO $\mathrm{O}_{2}$ (with $20 \%$ of Ti completed with c, Si and $(\mathrm{Ca}) . \quad$ ), e) and f) images exhibit NOAAs within Ti and O represent 82 to $93 \%$. All the percentages are given in mass.

\subsubsection{Analysis with respect to CW samples}

Similar to the NT samples, particles from CW samples produced under abrasion conditions are composed of ceramic matrix NOAA of $\mathrm{TiO}_{2}$ and composites of the compounds mentioned in the previous section. The largest aggregate size is close to $1.5 \mu \mathrm{m}$, Figure 15 . $\mathrm{TiO}_{2}$ was present in 8 out of the 12 grids. Out of the 12 grids, 3are quasi-pure submicronic NOAA of nano- $\mathrm{TiO}_{2}$. One particle showed a high concentration of $\mathrm{TiO}_{2}\left(41 \% \mathrm{TiO}_{2}, 46 \% \mathrm{O},<10 \%\right.$ of C). The sizes of the primary nano- $\mathrm{TiO}_{2}$ particles in the NOAA were between 129 and $149 \mathrm{~nm}$, with an average particle size of $134 \mathrm{~nm}$. The other particles mainly consists of the ceramic matrix.
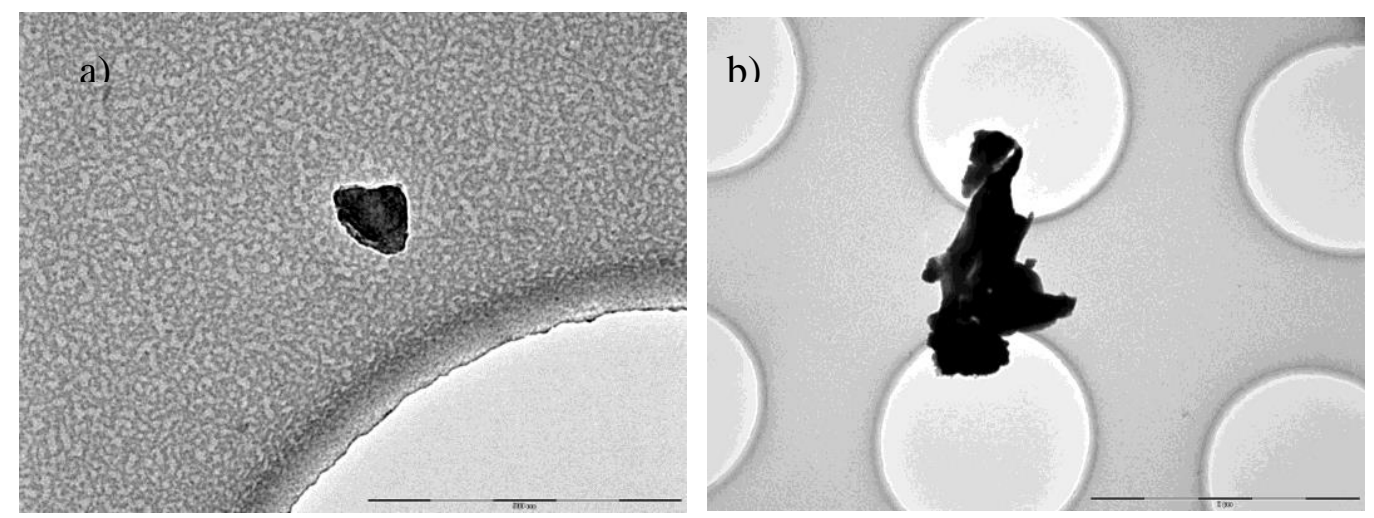

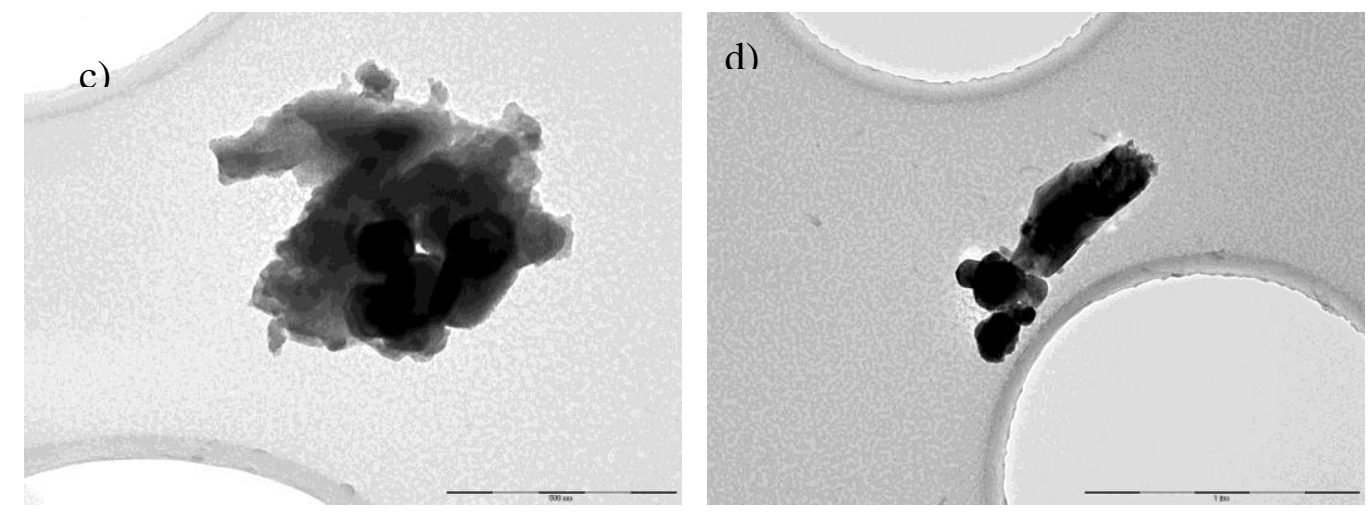

Figure 15 : particles or NOAA collected on the TEM grid during the abrasion test with CW sample. Nanoparticle in a) composite $\mathrm{Zn}(57 \%)$, Ni (19\%) Ti (10\%); Micronic particle in b) is dominated by Zn (67\%), Fe (11\%), Si ( $6 \%)$ and Ca (5

\%). c) composite containing nanoTiO 2 (with $29 \%$ of Ti and $50 \%$ of $\mathrm{O}$ in presence $\mathrm{Si}(13 \%)$. d) NOAA composed by Ti $(41 \%)$ and $O$ represent $46 \%$ with Carbon traces. All the percentages are given in mass.

\subsection{Analysis of the formed aerosol}

\subsubsection{Results from particle counting}

With the abrasion apparatus at rest, a very low background noise is detected., The abrasion process starts only after the two minutes of sampling background noise. The start of the abrasion test shows an immediate response, where the maximum values are reached within the initial 20 seconds (Figure 16). Under continuous abrasion for about 10 minutes, the samples were found to continuously release particles, although with a decrease in quantity (particle concentration). The particle release response of the tiles under the abrasion procedure differs from those made elsewhere (Shandilya et al. 2014, 2015). The weathered reference (NW) is 1.48 times more emissive than the reference (NT) one, whereas the weathered tile containing nano- $\mathrm{TiO}_{2}$ is less emissive than the unweathered tile (CT) (see Table 3). 


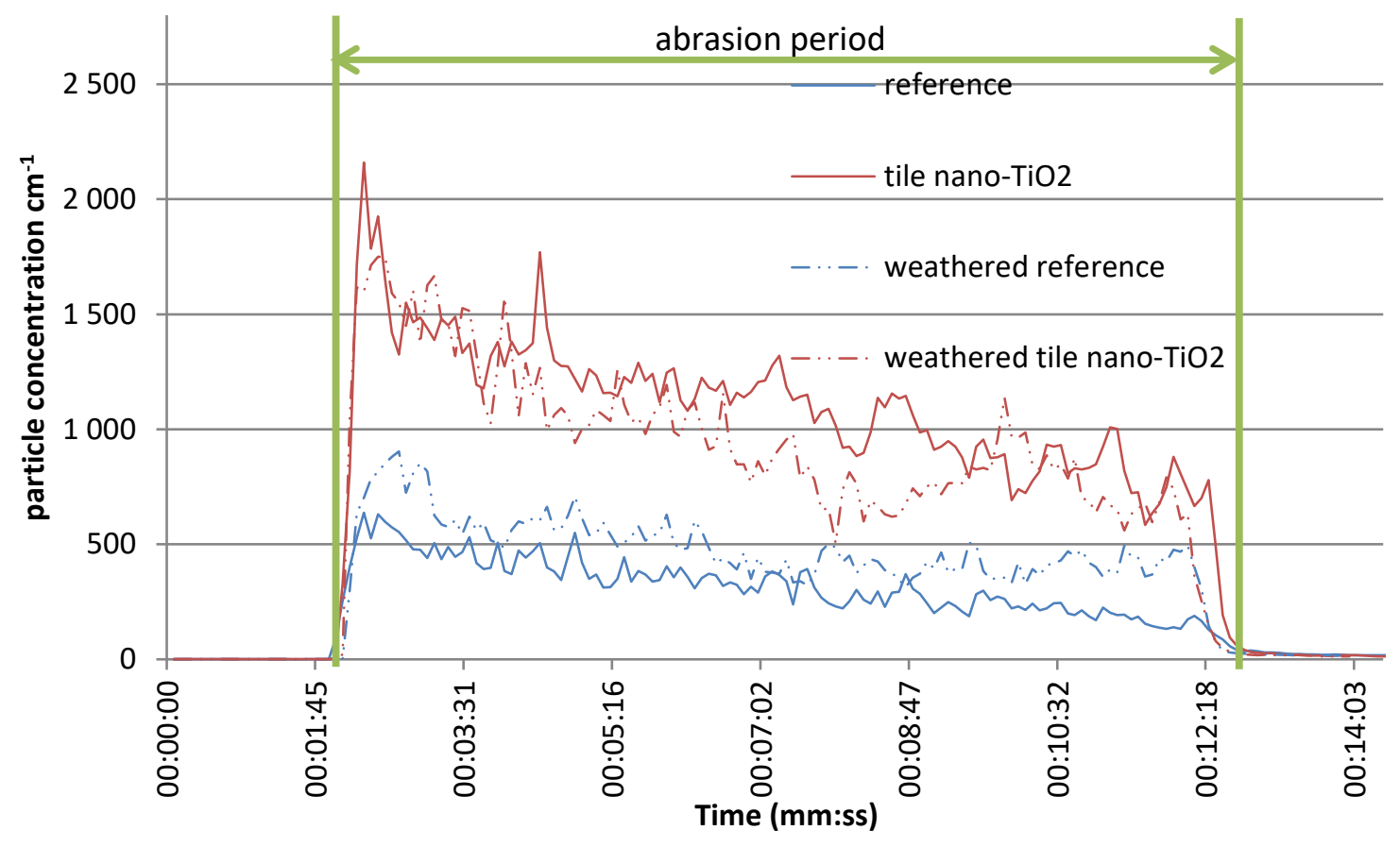

Figure 16: Linear representation of the emitted particle number concentration (4 $\mathrm{nm}$ to $3 \mu \mathrm{m})$ of reference or weathered reference and commercial nano-coated tiles and weathered nano-coated tiles under abrasion, plotted with time

Table 3: counting mean concentration during the abrasion test of 10 minutes duration

\begin{tabular}{|c|c|c|}
\hline $\begin{array}{c}\text { Counting } \\
\text { mean } \mathrm{cm}^{-}\end{array}$ & $\begin{array}{c}\text { non-coated } \\
\text { tile }\end{array}$ & coated tile \\
\hline not & 329 & 1112 \\
weathered & (NT) & (CT) \\
\hline weathered & 487 & 970 \\
& $(\mathrm{NW})$ & $(\mathrm{CW})$ \\
\hline
\end{tabular}


The mean particle concentration (by count) clearly shows that the coating of samples increases the sample's tendency to release aerosols, Table 3. The weathering leads to a significant increase $(+48 \%)$ in release for non-coated tiles, whereas the release tendency decreases slightly for coated tiles $(-10 \%)$.

\subsubsection{Results from granulometry}

A closer look to the number concentrations of the released aerosols (Table 4and Figure 17), show the mean modes for all samples to lie between the sizes of 407 and $476 \mathrm{~nm}$. For the noncoated and coated tiles, the mean mode shifts with weathering to lower values, respectively. The total counting obtained by addition of APS and SMPS measurements highlight higher emission for CT and CW samples (Table 4).

Almost the entire aerosol is composed of the so-called fine particles. However, the nanofraction counts for the nanocoated samples are found to be higher compared to the nontreated tiles. This tendency is particularly observed for the particles below $20 \mathrm{~nm}$ (Figure 17).

\subsubsection{Aerosol emission granulometry for non-coated tiles}

The average number concentration in the nanosized fraction are $31 \mathrm{~cm}^{-3}$ and $40 \mathrm{~cm}^{-3}$ for the non-treaded and weathered tiles, respectively. The relative nanosized fractions are $9.6 \%$ for the first, and $7.8 \%$ for the latter one. The number counts of micronic for the non-weathered and weathered tiles are $260 \mathrm{~cm}^{-3}$ and $410 \mathrm{~cm}^{-3}$, respectively. Here, the relative fractions are larger with $80.7 \%$ and $79.8 \%$, but an evolution with respect to the relative nanosized fraction is not observed.

In summary, the emissions of non-coated tiles increase slightly, however without significantly changing their PM1 fraction and with a slight decrease in particles in the nanosized fraction. 
For coated tiles, an average of $812 \mathrm{~cm}^{-1}$ (71.4\% of the total aerosol) for the non-weathered and $745 \mathrm{~cm}^{-1}$ (77 \% of the total aerosol) for weathered tiles is observed under the PM1 fraction. Furthermore, an average of $80 \mathrm{~cm}^{-1}$ ( $7 \%$ of the total aerosol) for non-weathered tiles and $78 \mathrm{~cm}^{-1}$ ( $8 \%$ of the total aerosol) for the weathered ones are observed is observed for the nanosize fraction. Hence, the effects of weathering include slight decrease in the total aerosol emission level but on the other hand it increases the size shift towards the micronic and the nanosized fractions.

Table 4: APS/SMPS distribution and total concentration. These results are obtained by merging APS and SMPS distribution using data merge software (TSI)

\begin{tabular}{|c|c|c|c|c|}
\hline Sample & $\begin{array}{c}\text { Non-coated tile } \\
(\mathrm{NT})\end{array}$ & Coated tile & Non-coated tile & Coated tile, \\
& & $(\mathrm{CT})$ & weathered & weathered (CW) \\
\hline Mean mode (nm) & 476 & 470 & 407 & 437 \\
\hline Median (nm) & 477 & 515 & 480 & 477 \\
\hline $\begin{array}{c}\text { Mean size (nm) } \\
\text { concentration }\end{array}$ & 653 & 775 & 757 & \\
\hline $\begin{array}{c}\text { average particle } \\
\text { (cm }\end{array}$ & 266 & 1140 & 514 & \\
\hline
\end{tabular}




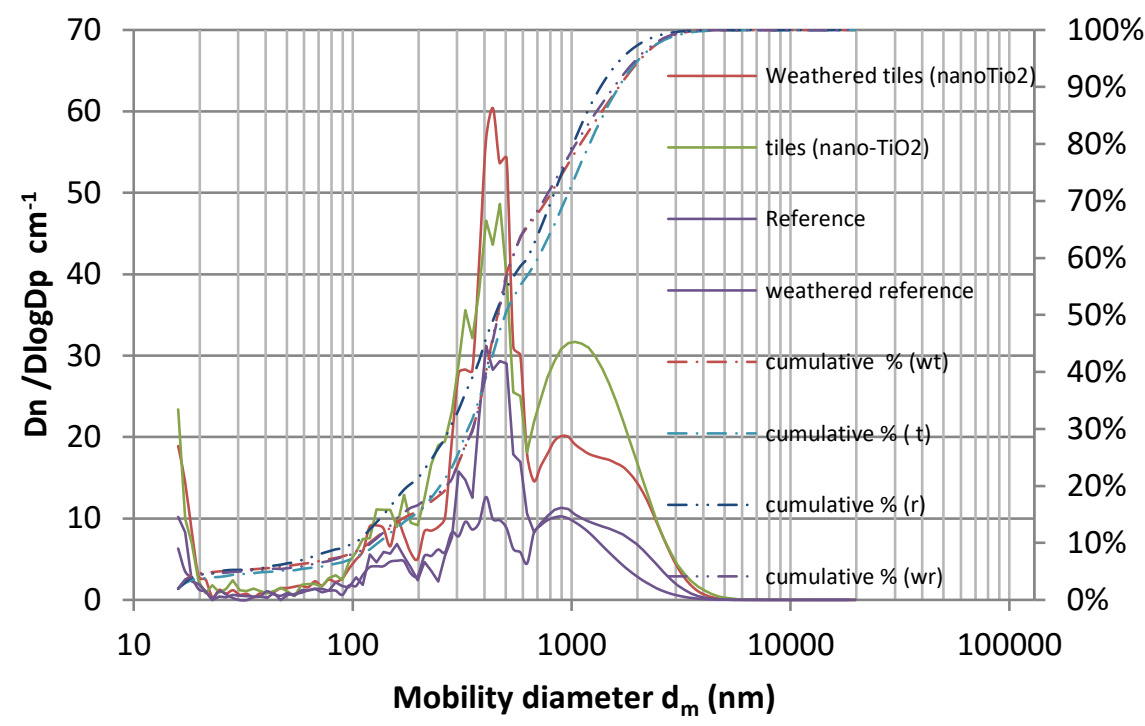

Figure 17: Particle size distributions of four tests; Data merge software from TSI has been used to merge APS and SMPS size distributions. Two curves correspond to unweathered samples i.e. reference and nanocoated tiles and the two others to the weathered ones. Each sizing curve corresponds to the average of two tests. The dotted curve is the cumulative of the size distribution in percentage.

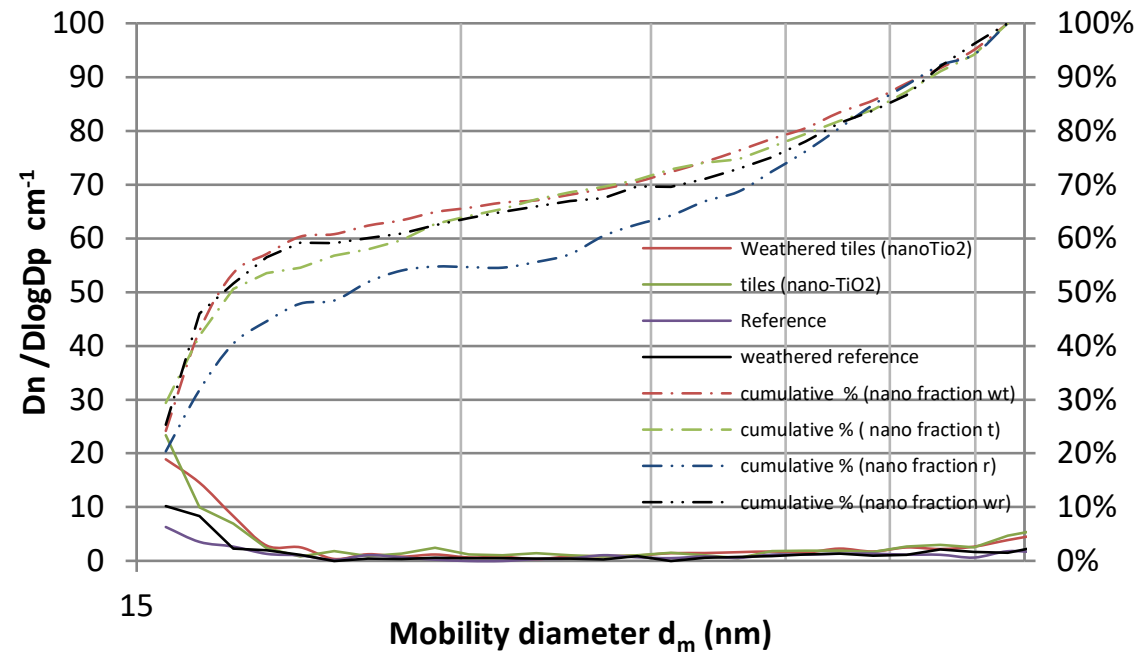

Figure 18: Particle size distributions of four tests in the nanosized range; two corresponding to unweathered samples i.e. reference and nanocoated tile and the two others to the weathered ones. Again, each sizing curve corresponds to the average of two tests. The dotted curve is the cumulative of the size distribution in percentage.

\subsubsection{Results summarized in boxplots}

The overall fluctuation of the particle concentrations along the multimodal size distribution curves makes it impossible to clearly understand the effects of firstly, the coating and 
secondly, the weathering of tiles. For example, the presence of micron particles seem to be particularly affected by the weathering process (Figure 17). As shown before (section 2.6), a boxplot approach and using suitable descriptive statistics can help to discern the trends in the changing particle evolution. The utility of such a representation has been demonstrated in previous studies (Huang et al. 2012). Figure 19 shows the measured overall particle concentrations from Figure 17 for the particles in the size range of 15.4-20 $535 \mathrm{~nm}$ in the boxplots with mean value and normal standard deviation. Additionally, the significance level of average 1.5 IRQ (interquartile range) is marked as the whiskers. The median of a population is generally located between the mode and the average (Sato 1997; Abdous and Theodorescu 1998; Dagnelie 2007) and was also found to be the case for all the four samples. Maximum values are observed near $15-20 \mathrm{~nm}$ particularly for coated and non-coated tiles, as well as the weathered tiles. The non-treated weathered tiles show similar results in form but with lower counts. The cumulative curves in Figure 18 confirm these points for all tiles with the exception of the the non-treated and non-weathered tiles.

In our case, the distributions' skewness are detected due to the systematic vicinity of the median to the first quartile for all the samples.

\subsubsection{Influence of the coating}

The coating of the tiles leads to the particle emissions shift towards the bigger particle sizeswith whiskers after coating beyond $2000 \mathrm{~nm}$. The interquartile range (IRQ) is also bigger in presence of nano- $\mathrm{TiO}_{2}$. Whiskers are $>100 \mathrm{~nm}$ for $\mathrm{NT}$ and equal to $100 \mathrm{~nm}$ for CT samples. The interquartile range (IRQ) is smaller in presence of nano- $\mathrm{TiO}_{2}$.

\subsubsection{Influence of the weathering}

For the non-coated tiles, a slight shift towards bigger particle sizes is observed due to weathering. Whiskers are below $2000 \mathrm{~nm}$. The interquartile range (IRQ) is lower after 
weathering. For the coated tiles, a slight shift towards smaller particle sizes can be observed for the IRQ and the median.

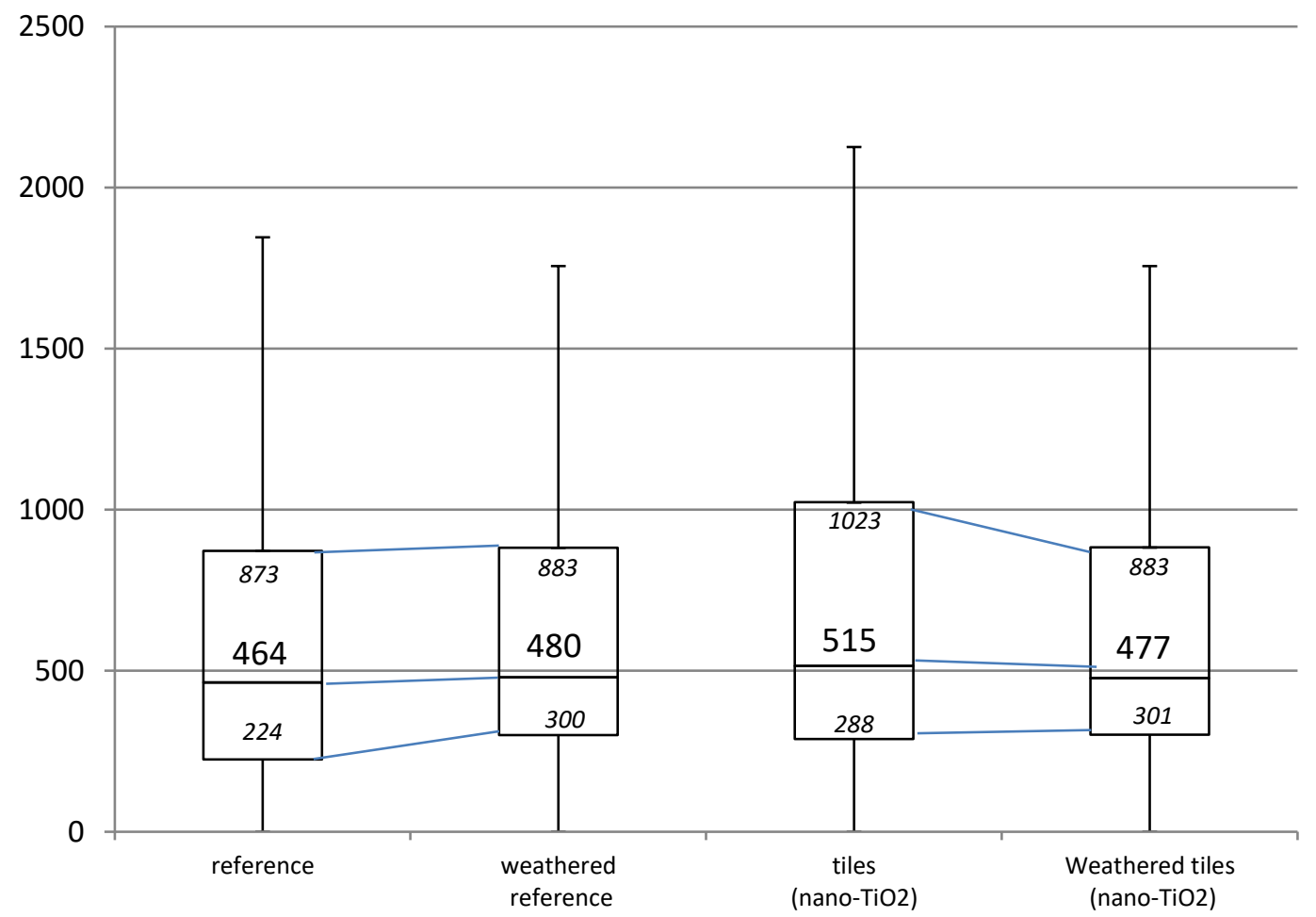

Figure 19: Box plot summarizing the sizing distribution of the total aerosol generated by aerosol

When comparing CT with CW samples, a slight shift to smaller particles can be observed. Whiskers are equal to $100 \mathrm{~nm}$ for CT and below $100 \mathrm{~nm}$ for WT. The interquartile range (IRQ) is lower after weathering. 


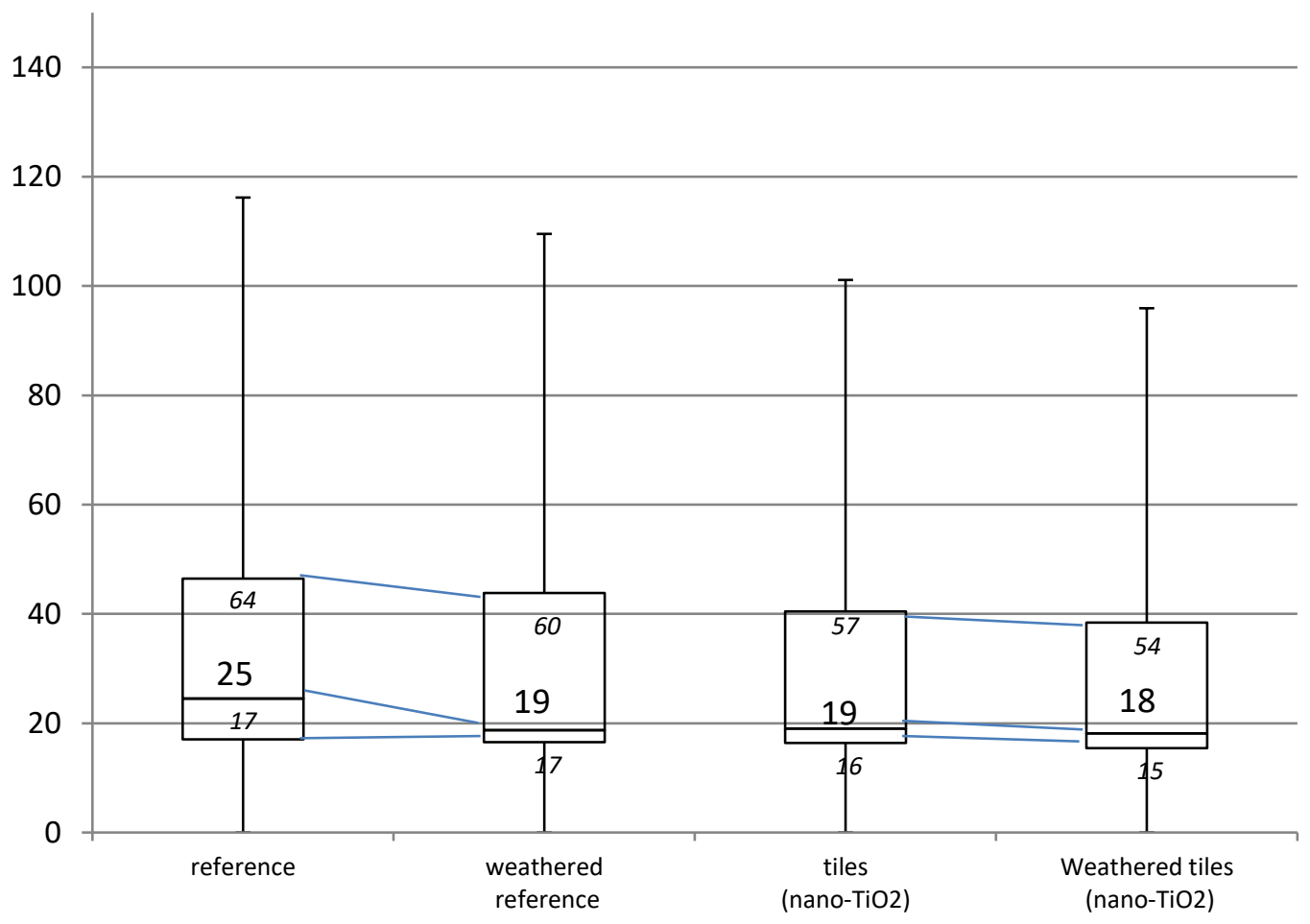

Figure 20: Box plot summarizing the sizing distribution of the nanosized fraction of the aerosol generated by aerosol.

Focusing the study on the nanofraction of weathered samples, the boxplot analysis reveals a stable situation for CT samples with a slight decrease of the IRQ range and a shift to smaller particles.

\subsection{Summary of the results}

The study presented here focuses on properties of the materials used in construction materials i.e. tiles used in (Bressot et al. 2016). The main observations made have been

i) a moderate wear induced by the ageing process in the climate chamber. Nano- $\mathrm{TiO}_{2}$ depositions are involved in this ageing/ weathering process.

ii) a clear increase in the particle counts for the weathered NT with respect to the CPC or the APS and SMPS measurements.

iii) a slight decrease in the particle counts for the CT samples with weathering

iv) a shift of the mean to smaller sizes for the NT as well as the NW samples due to weathering 
v) also, with the weathering action, a net shift of the median size of the particles towards smaller values for the CT samples, but no significant shift for the NT samples

vi) Thereof, IRQ

a. is reduced by weathering

b. is shifted to bigger particles for the NT samples and towards smaller particles for the CT samples.

c. by weathering, slightly shifted to smaller particles and reduced for the NT samples for the nanofraction.

d. with the weathering, slightly shifting to smaller particles and reduced for the CT samples for the nanofraction.

\section{DISCUSSION}

The weathering action has only a minor effect on the reference samples and leads to generation of bigger, but still submicronic debris particles in nature. A reverse effect of the weathering is observed with CT samples which leads to release of smaller sized particles. Weathering has almost no detectable effect on nano-fraction. Obviously, the weathering action separates micronic NOAA of nano- $\mathrm{TiO}_{2}$ in submicronic and compact ones. This process results in quasi-stable counts.

\subsection{Interpretations with respect to mineral compounds of the functional material}

Chabas et al. (Chabas, Lombardo, Cachier, Pertuisot, Oikonomou, Falcone, Verita, et al. 2008) have investigated the durability of self-cleaning glass coated with nano- $\mathrm{TiO}_{2}$. SEM investigations and chemical analyses on the samples exposed to ambient conditions for 6,12 , and 24 months showed no evidence of a significant weathering effect on the surfaces or loss of Ti (Chabas, Lombardo, Cachier, Pertuisot, Oikonomou, Falcone, Verità, et al. 2008). In addition, the photo-dissociation of HONO in the near-UV range of the solar spectrum 
represents an important source of hydroxyl radicals $(\mathrm{OH})$, particularly indoor (Alvarez et al. 2014; Alvarez et al. 2012; Gomez Alvarez et al. 2013).

The unique evolution clearly assigned to the weathering effects is the decrease in the presence of calcium on the tile surfaces which is probably attributed to the loss of $\mathrm{CaO}$. Calcium oxide is a compound of the inorganic adhesive and seems to be the unique source of $\mathrm{Ca}$ which may decrease the concentration of calcium by dissolution in the water.

The emissions from the abrasion test are mostly in the "Respirable aerosol fraction" (or alveolar fraction), which is the sub fraction of the inhaled particles $\left[d_{\mathrm{ae}}<10 \mu \mathrm{m}\right]$ that penetrates into the alveolar region of the lung (Nieboer et al. 2005). With regards to changes in size distribution due to weathering and the CIPR model (CRP 1994), the weathered and unweathered nanomaterial should be collected in a similar manner in the breathing zone.

\subsection{Interpretations with respect to the material's fate}

Figure 21 shows a schematic representative of the evolution of the aerosol formation from tiles under abrasion, be it coated and not coated with $\mathrm{TiO}_{2}$ coated or not. The picture completes the findings presented by (Shandilya et al. 2016). There, a further, intermediate aerosolization phase was observed, corresponding to the deterioration and failure of the coating. The case presented here exhibits, in essence, an universal evolution of the aerosolization of a monolithic material, notwithstanding of the material's history - even a history of 7 months of accelerated weathering, as studied by (Science for environmental policy 2015), does not change the picture. 


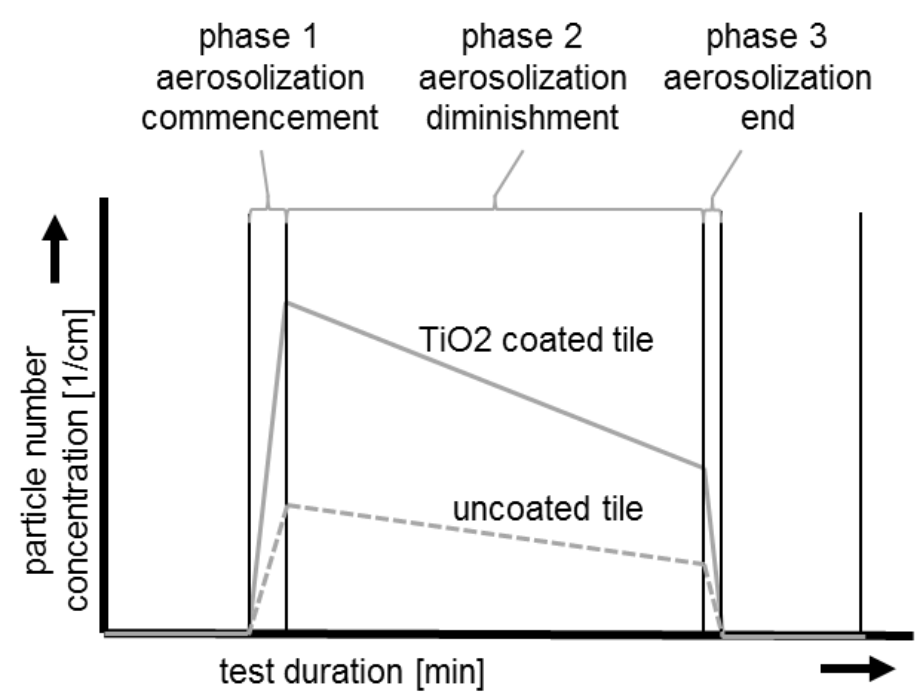

Figure 21: Evolution of the aerosol formation level during abrasion

The superposed two materials with similar hardness, tile and coating, form a somewhat smeared continuum. The rather homogeneous and vertically constant hardness in direction of the abrader's penetration is diminished only by the horizontally corrugated surface.

\section{CONCLUSION}

Conscious of the rising nosocomial risks of cross infection, decision makers in the healthcare sector seek sustainable techniques for effective antimicrobial stewardship in healthcare settings. Manufacturers offer solutions for floorings and wallcoverings based on $\mathrm{TiO}_{2}$, considered today to be the only photocatalytic material suitable for commercial use. However, these building materials involve the risk of the aerosolization of the antimicrobial coating and thus its inhalation by healthcare personnel and patients.

The present study affirms this risk from aerosolization of the antimicrobial coating. While no free, i.e. individual $\mathrm{TiO}_{2}$ particles, were detected in the aerosol debris generated due to the abrasion of the sample, but submicronic and inhalable NOAA containing Ti have been found. 
These objects constitute an important part of the detected aerosols, especially at the commencement of a material's wear process.

The evolution of this process with time of use, i.e. the impact of ageing, which could potentially change its emissivity, seems not to reduce its risk of emission, which persists to be substantial even over seven months of accelerated ageing. In conclusion, time does not mend the inherent product risks. Consequently, the nanomaterial investigated here should rather be avoided in healthcare settings or the material properties need to be improved to avoid release of free NOAAs.

At material level, since the coating magnifies the product emissivity, the study of these emissions should be at the heart of the further developments of antibacterial building solutions. At present, new $\mathrm{TiO}_{2}$ deposition techniques are studied, presumably allowing for palliating the material's emissivity albeit preserving its antimicrobial product properties.

At the health and safety level, alike the situation in other sectors involving the release of other mineral particles (Madl et al. 2008), the study of the occupational health hazards will take a considerable amount of time. Risk evaluation both at 'bed level' as well as 'staff level' make pragmatic approaches necessary, analogous to the evaluation at the production level (Bressot et al. 2018).

In conclusion, Figure 22 illustrates the dichotomy of the use of nanomaterials in the healthcare sector, which might lead to a drawback when compared to the 'beating the nosocomial- loop-paradigm' originally presented by (Page, Wilson, and Parkin 2009). 

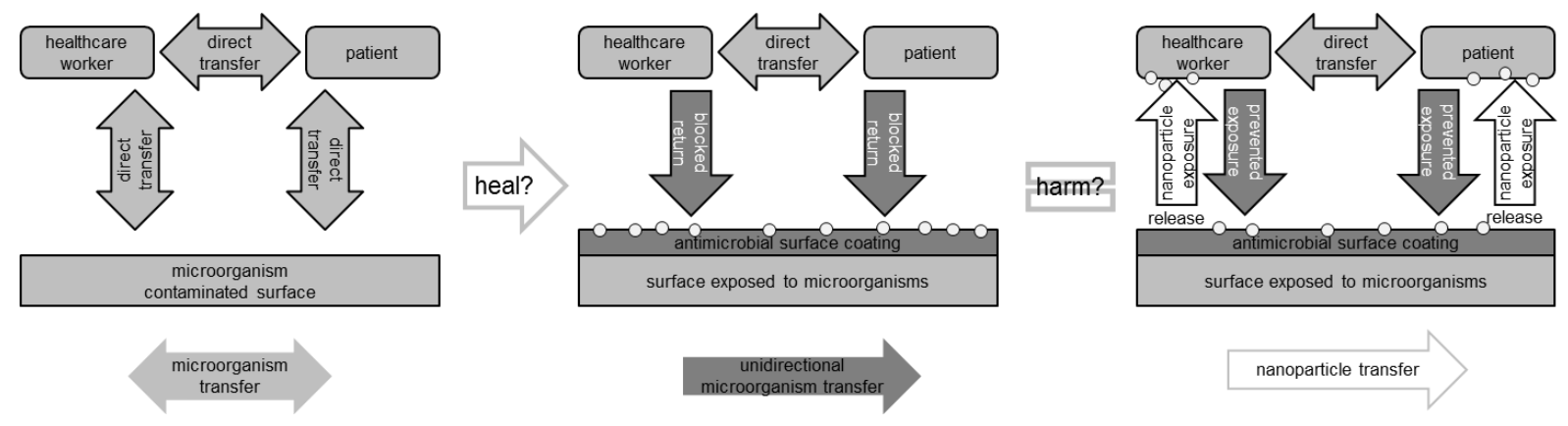

Figure 22: The role of surfaces and antimicrobial surface coatings in the epidemiology of HAIs - beating the "nosocomial infection loop", after (Page, Wilson, and Parkin 2009), and their possible resulting exposure of patients and healthcare workers

\section{Acknowledgments}

The authors would like to thank the French Ministry of Environment (Program 190), ANSES (Nanodata Project, APR ANSES 2012). The authors furthermore acknowledge the contributions of the French Ministry in charge of Environment, the DAMPEC scheme and the EUPLAPSCH network. Experimental work of Morgane Dalle and the manuscript's editing by Dr. Somik Chakravarty is gratefully acknowledged.

\section{REFERENCES}

84, ASTM C501 -. 2015. Standard Test Method for Relative Resistance to Wear of Unglazed Ceramic Tile by the Taber Abraser. ASTM C501 - 84.

Abdous, B., and R. Theodorescu. 1998. Mean, median, mode IV. Statistica Neerlandica 52 (3):356.

Alvarez, E. G., M. Sorgel, S. Gligorovski, S. Bassil, V. Bartolomei, B. Coulomb, C. Zetzsch, and H. Wortham. 2014. Light-induced nitrous acid (HONO) production from NO2 heterogeneous reactions on household chemicals. Atmospheric Environment 95:391-399.

Alvarez, e. G., h. Wortham, r. Strekowski, c. Zetzsch, and s. Gligorovski. 2012. Atmospheric Photosensitized Heterogeneous and Multiphase Reactions: From Outdoors to Indoors. Environmental Science \& Technology 46 (4):1955-1963.

B. S. Atiyeh, M. Costagliola, S. N. Hayek and S. A. Dibo. 2007. Effect of silver on burn wound infection control and healing: Review of the literature. Burns.

Bernard, Bruce K., Merrill R. Osheroff, Andreas Hofman, and John H. Mennear. 1989. Toxicology and carcinogenesis studies of dietary titanium dioxide-coated mica in male and female Fischer 344 rats. Journal of Toxicology and Environmental Health 28 (4):415-426.

Bressot, C., C. Pagnoux, N. Manier, O. Aguerre Chariol, and M. Morgeneyer. 2016. Environmental release of engineered nanomaterials from commercial tiles under standardized abrasion conditions. Journal of Hazardous Materials. 
Bressot, Christophe, Neeraj Shandilya, Thangavalu Jayabalan, Guillaume Fayet, Matthias Voetz, Laurent Meunier, Olivier Le Bihan, Olivier Aguerre-Chariol, and Martin Morgeneyer. 2018. Exposure assessment of Nanomaterials at production sites by a Short Time Sampling (STS) approach Strategy and first results of measurement campaigns. Process Safety and Environmental Protection.

C241, ASTM. Standard Test Method for Abrasion Resistance of Stone Subjected to Foot Traffic. ASTM C241

Chabas, A, T Lombardo, H Cachier, MH Pertuisot, K Oikonomou, R Falcone, M Verita, and F Geotti-Bianchini. 2008. Behaviour of self-cleaning glass in urban atmosphere. Building and environment 43 (12):21242131.

Chabas, A., T. Lombardo, H. Cachier, M. H. Pertuisot, K. Oikonomou, R. Falcone, M. Verità, and F. GeottiBianchini. 2008. Behaviour of self-cleaning glass in urban atmosphere. Building and Environment 43 (12):2124-2131.

CRP. 1994. Human Respiratory Tract Model for Radiological Protection. Ann. ICRP Publication 66 ICRP 24 ((1-3)).

D4060, ASTM. 2007. Standard Test Method for the Abrasion of Organic Coatings by the Taber Abraser. ASTM international ASTM D4060.

D6695, ASTM. Standard Practice for Xenon-Arc Exposures of Paint and Related Coatings. ASTM D6695.

Dagnelie, P. 2007. statistique théorique et appliquée. Edited by e. edition. 2 vols. Bruxelles: de broeck.

Donlan, R. M. 2002. Biofilms: microbial life on surfaces. Emerg Infect Dis 8 (9):881-90.

Ducel, G, J Fabry, and L Nicolle. 2002. Prevention of hospital acquired infections: a practical guide. Prevention of hospital acquired infections: a practical guide (Ed. 2).

EN660-2. Resilient floor coverings - Determination of wear resistance - Part 2: Frick-Taber Test.

Fonseca, A. S., A. Maragkidou, M. Viana, X. Querol, K. Hameri, I. de Francisco, C. Estepa, C. Borrell, V. Lennikov, and G. F. de la Fuente. 2016. Process-generated nanoparticles from ceramic tile sintering: Emissions, exposure and environmental release. Sci Total Environ.

G151, ASTM. Standard Practice for Exposing Nonmetallic Materials in Accelerated Test Devices that Use Laboratory Light Sources. ASTM G151.

G155, ASTM. Standard Practice for Operating Xenon Arc Light Apparatus for Exposure of Non-Metallic Materials. ASTM G155.

Gomez Alvarez, E., D. Amedro, C. Afif, S. Gligorovski, C. Schoemacker, C. Fittschen, J.-F. Doussin, and H. Wortham. 2013. Photolysis of nitrous acid as a primary source of $\mathrm{OH}$ radicals indoors. . Proc. Natl. Acad. Sci. U. S. A. 33: 13294e13299.

Gunawardana, Manju. 2013. Nanotechnology in Healthcare Acquired Infectious Decease Control Application Protocol-Heterogeneous Photocatalytic Air Disinfection \& Nano Silver Surface Disinfection.

Hashimoto, Kazuhito, Hiroshi Irie, and Akira Fujishima. 2005. TiO2Photocatalysis: A Historical Overview and Future Prospects. Japanese Journal of Applied Physics 44 (12):8269-8285.

Heinrich, U., R. Fuhst, S. Rittinghausen, O. Creutzenberg, B. Bellmann, W. Koch, and K. Levsen. 1995. Chronic Inhalation Exposure of Wistar Rats and two Different Strains of Mice to Diesel Engine Exhaust, Carbon Black, and Titanium Dioxide. Inhalation Toxicology 7 (4):533-556.

Huang, G., J. H. Park, L. G. Cena, B. L. Shelton, and T. M. Peters. 2012. Evaluation of Airborne Particle Emissions from Commercial Products Containing Carbon Nanotubes. Journal of Nanoparticle Research: An Interdisciplinary Forum for Nanoscale Science and Technology 14 (11):1231.

Inderdeep Singh Walia, and Rajiv M Borle. 2012. Manual of Operating Room Discipline \& Protocol: Jaypee Brothers Medical Publishers.

Kamsu-Foguem, Bernard, Germaine Tchuenté-Foguem, and Clovis Foguem. 2014. Verifying a medical protocol with temporal graphs: The case of a nosocomial disease. Journal of critical care 29 (4):690. e1-690. e9.

Kargupta, R., S. Bok, C. M. Darr, B. D. Crist, K. Gangopadhyay, S. Gangopadhyay, and S. Sengupta. 2014. Coatings and surface modifications imparting antimicrobial activity to orthopedic implants. Wiley Interdiscip Rev Nanomed Nanobiotechnol 6 (5):475-95.

Krewski, Daniel, Robert A. Yokel, Evert Nieboer, David Borchelt, Joshua Cohen, Jean Harry, Sam Kacew, Joan Lindsay, Amal M. Mahfouz, and Virginie Rondeau. 2007. Human Health Risk Assessment for Aluminium, Aluminium Oxide, and Aluminium Hydroxide. Journal of Toxicology and Environmental Health, Part B 10 (sup1):1-269.

Lansdown, A. B. G. 2006. Silver in Healthcare: an Enigma and Pathological Fascination. The Bulletin of The Royal College of Pathologists.

Le Bihan, O, M Morgeneyer, N Shandilya, O Aguerre Chariol, C Bressot, U Vogel, K Savolainen, Q Wu, M Van Tongeren, and D Brouwer. 2014. Handbook of nanosafety-measurement, exposure and toxicology. Emission Chambers: A Method for Nanosafety:226-231. 
Lee, Byung-Mu, and Sam Kacew. 2012. Lu's basic toxicology: fundamentals, target organs, and risk assessment: CRC press.

Madl, A. K., E. P. Donovan, S. H. Gaffney, M. A. McKinley, E. C. Moody, J. L. Henshaw, and D. J. Paustenbach. 2008. State-of-the-science review of the occupational health hazards of crystalline silica in abrasive blasting operations and related requirements for respiratory protection. J Toxicol Environ Health B Crit Rev 11 (7):548-608.

Magill, S. S., J. R. Edwards, W. Bamberg, Z. G. Beldavs, G. Dumyati, M. A. Kainer, R. Lynfield, M. Maloney, L. McAllister-Hollod, J. Nadle, S. M. Ray, D. L. Thompson, L. E. Wilson, S. K. Fridkin, Infections Emerging Infections Program Healthcare-Associated, and Team Antimicrobial Use Prevalence Survey. 2014. Multistate point-prevalence survey of health care-associated infections. N Engl J Med 370 (13):1198208.

NF. Peintures et vernis - Méthodes d'exposition à des sources lumineuses de laboratoire - Partie 1 : lignes directrices générales. 16747-1 : Paints and varnishes - Methods of exposure to laboratory light sources - Part 1: General guidance: AFNOR; 2014. p. 36. ISO. NF EN ISO 16474-1

Nieboer, E., Y. Thomassen, V. Chashchin, and J. O. Odland. 2005. Occupational exposure assessment of metals. J Environ Monit 7 (5):412-5.

Page, Kristopher, Michael Wilson, and Ivan P. Parkin. 2009. Antimicrobial surfaces and their potential in reducing the role of the inanimate environment in the incidence of hospital-acquired infections. Journal of Materials Chemistry 19 (23):3819.

Palgrave, I. P. Parkin and R. G. 2005. Self-cleaning coatings. J. Mater. Chem.

Park, K. D., Y. S. Kim, D. K. Han, Y. H. Kim, E. H. Lee, H. Suh, and K. S. Choi. 1998. Bacterial adhesion on PEG modified polyurethane surfaces. Biomaterials 19 (7-9):851-9.

Paustenbach, D. J. 2000. The practice of exposure assessment: a state-of-the-art review. J Toxicol Environ Health B Crit Rev 3 (3):179-291.

Pellicelli, G., A. Tucci, and E. Rambaldi. 2010. Photocatalytic ceramic article and method for its production: Google Patents.

Prevention, Centers for Desease Control and. 2014. https://www.cdc.gov/hai/surveillance/.

Sato, M. 1997. Some remarks on the mean, median, mode and skewness. Australian Journal of Statistics 39 (2):219-224.

Science for environmental policy, European commission. 2015. Nanocoating on buildings releases potentially toxic particles to the air, , .

Selwyn, Sydney. 1991. Hospital infection: the first 2500 years. Journal of Hospital Infection 18:5-64.

Shandilya, N., C. Bressot, O. Le Bihan, and M. Morgeneyer. 2016. Approximate prediction of service life durations of nano-structured coatings, accepted. Newsletter, WHO collaborating center for housing and health.

Shandilya, N., O. Le Bihan, C. Bressot, and M. Morgeneyer. 2014. Evaluation of the Particle Aerosolization from $\mathrm{n}$-TiO2 Photocatalytic Nanocoatings under Abrasion. Journal of Nanomaterials.

- - - 2015. Emission of Titanium Dioxide Nanoparticles from Building Materials to the Environment by Wear and Weather. Environmental Science \& Technology 49 (4):2163-2170.

Shandilya, N., O. Le Bihan, and A. Morgeneyer. 2014. A Review on the Study of the Generation of (Nano)particles Aerosols during the Mechanical Solicitation of Materials. Journal of Nanomaterials.

Shandilya, N., O. Le Bihan, and M. Morgeneyer. 2014. Effect of the Normal Load on the Release of Aerosol Wear Particles During Abrasion. Tribology Letters 55 (2):227-234.

Shi, H., R. Magaye, V. Castranova, and J. Zhao. 2013. Titanium dioxide nanoparticles: a review of current toxicological data. Part Fibre Toxicol 10:15.

Skocaj, M., M. Filipic, J. Petkovic, and S. Novak. 2011. Titanium dioxide in our everyday life; is it safe? Radiol Oncol 45 (4):227-47.

Swartjes, J. J. T. M., P. K. Sharma, T. G. van Kooten, H. C. van der Mei, M. Mahmoudi, H. J. Busscher, and E. T. J. Rochford. 2015. Current Developments in Antimicrobial Surface Coatings for Biomedical Applications. Current Medicinal Chemistry 22 (18):2116-2129.

T. Matsunaga, R. Tomoda, T. Nakajima and H. Wake. 1985. Photoelectrochemical Sterilization of Microbial-Cells by Semiconductor Powders. FEMS Microbiology Letters.

Takayama, S., M. Hirohashi, M. Kato, and H. Shimada. 1995. Toxicity of quinolone antimicrobial agents. J Toxicol Environ Health 45 (1):1-45.

Talebian, Nasrin, Mohammad Reza Nilforoushan, and Elahe Badri Zargar. 2011. Enhanced antibacterial performance of hybrid semiconductor nanomaterials: $\mathrm{ZnO} / \mathrm{SnO} 2$ nanocomposite thin films. Applied Surface Science 258:547-555. 
Thorén, Sven A. 1992. Calorimetry: A new quantitative in vitro method in cell toxicology. a dose/effect study of alveolar macrophages exposed to particles. Journal of Toxicology and Environmental Health 36 (4):307-318.

Tollefsen, K. E., and S. Kacew. 2017. 6TH NORWEGIAN ENVIRONMENTAL TOXICOLOGY SYMPOSIUM: Assessing and solving environmental challenges in a multiple stressor world. J Toxicol Environ Health A:1-2.

Trouiller, B., R. Reliene, A. Westbrook, P. Solaimani, and R. H. Schiestl. 2009. Titanium dioxide nanoparticles induce DNA damage and genetic instability in vivo in mice. Cancer Res 69 (22):8784-9.

W. A. Jacoby, P. C. Maness, E. J. Wolfrum, D. M. Blake and J. A. Fennell. 1998. Mineralization of bacterial cell mass on a photocatalytic surface in air. Environmental Science \& Technology.

Zhao, J., and V. Castranova. 2011. Toxicology of nanomaterials used in nanomedicine. J Toxicol Environ Health B Crit Rev 14 (8):593-632. 